\title{
On the importance of atmospheric loss of organic nitrates by aqueous-phase $\cdot$ OH oxidation
}

\author{
Juan Miguel González-Sánchez ${ }^{1,2}$, Nicolas Brun ${ }^{1,2}$, Junteng Wu ${ }^{1}$, Julien Morin ${ }^{1}$, Brice Temime-Roussel ${ }^{1}$, \\ Sylvain Ravier ${ }^{1}$, Camille Mouchel-Vallon ${ }^{3}$, Jean-Louis Clément ${ }^{2}$, and Anne Monod $^{1}$ \\ ${ }^{1}$ Aix Marseille Univ, CNRS, LCE, Marseille, France \\ ${ }^{2}$ Aix Marseille Univ, CNRS, ICR, Marseille, France \\ ${ }^{3}$ Laboratoire d'Aérologie, Université de Toulouse, CNRS, UPS, Toulouse, France
}

Correspondence: Juan Miguel González-Sánchez (juanmiguelgs93@gmail.com) and Anne Monod (anne.monod@univ-amu.fr)

Received: 10 July 2020 - Discussion started: 9 October 2020

Revised: 16 January 2021 - Accepted: 21 February 2021 - Published: 30 March 2021

\begin{abstract}
Organic nitrates are secondary species in the atmosphere. Their fate is related to the chemical transport of pollutants from polluted areas to more distant zones. While their gas-phase chemistry has been studied, their reactivity in condensed phases is far from being understood. However, these compounds represent an important fraction of organic matter in condensed phases. In particular, their partition to the aqueous phase may be especially important for oxidized organic nitrates for which water solubility increases with functionalization. This work has studied for the first time the aqueous-phase $\cdot \mathrm{OH}$-oxidation kinetics of four alkyl nitrates (isopropyl nitrate, isobutyl nitrate, 1-pentyl nitrate, and isopentyl nitrate) and three functionalized organic nitrates $(\alpha$-nitrooxyacetone, 1-nitrooxy-2-propanol, and isosorbide 5-mononitrate) by developing a novel and accurate competition kinetic method. Low reactivity was observed, with $k_{\mathrm{OH}}$ ranging from $8 \times 10^{7}$ to $3.1 \times 10^{9} \mathrm{~L} \mathrm{~mol}^{-1} \mathrm{~s}^{-1}$ at $296 \pm 2 \mathrm{~K}$. Using these results, a previously developed aqueous-phase structure-activity relationship (SAR) was extended, and the resulting parameters confirmed the extreme deactivating effect of the nitrate group, up to two adjacent carbon atoms. The achieved extended SAR was then used to determine the -OH-oxidation rate constants of 49 organic nitrates, including hydroxy nitrates, ketonitrates, aldehyde nitrates, nitrooxy carboxylic acids, and more functionalized organic nitrates such as isoprene and terpene nitrates. Their multiphase atmospheric lifetimes towards $\cdot \mathrm{OH}$ oxidation were calculated using these rate constants, and they were compared to their gas-phase lifetimes. Large differences were observed, espe-
\end{abstract}

cially for polyfunctional organic nitrates: for $50 \%$ of the proposed organic nitrates for which the $\cdot \mathrm{OH}$ reaction occurs mainly in the aqueous phase (more than $50 \%$ of the overall removal), their $\cdot \mathrm{OH}$-oxidation lifetimes increased by $20 \%$ to $155 \%$ under cloud/fog conditions (liquid water content $\mathrm{LWC}=0.35 \mathrm{~g} \mathrm{~m}^{-3}$ ). In particular, for $83 \%$ of the proposed terpene nitrates, the reactivity towards $\cdot \mathrm{OH}$ occurred mostly $(>98 \%)$ in the aqueous phase, while for $60 \%$ of these terpene nitrates, their lifetimes increased by $25 \%$ to $140 \%$ compared to their gas-phase reactivity. We demonstrate that these effects are of importance under cloud/fog conditions but also under wet aerosol conditions, especially for the terpene nitrates. These results suggest that considering aqueous-phase $\cdot \mathrm{OH}$-oxidation reactivity of biogenic nitrates is necessary to improve the predictions of their atmospheric fate.

\section{Introduction}

Nitrogen oxides $\left(\mathrm{NO}_{x}=\cdot \mathrm{NO}+\cdot \mathrm{NO}_{2}\right)$ intensely impact air quality and the environment as they play key roles in the production of relevant air pollutants such as ozone $\left(\mathrm{O}_{3}\right)$, nitrous acid (HONO), nitric acid $\left(\mathrm{HNO}_{3}\right)$, and secondary organic aerosol (SOA). Their atmospheric chemistry controls the concentrations of the three main oxidants, $\mathrm{O}_{3}, \cdot \mathrm{OH}$, and $\mathrm{NO}_{3} \cdot$ radicals. The past few decades have witnessed important reductions in $\mathrm{NO}_{x}$ direct emissions in Europe or North America, resulting in changes in their atmospheric fate, by 
increasing the relative importance of their conversion to organic nitrates (Romer Present et al., 2020). The latter are secondary organic compounds, which are formed by the reactivity of $\mathrm{NO}_{x}$ with volatile organic compounds (VOCs). Owing to their long atmospheric lifetimes (much longer than for $\mathrm{NO}_{x}$ ), organic nitrates can be transported from polluted to remote areas. During their long-range transport, these compounds may (1) release back $\mathrm{NO}_{x}$ far from $\mathrm{NO}_{x}$ sources via direct photolysis and/or $\cdot \mathrm{OH}$ oxidation or (2) act as a definitive sink of atmospheric $\mathrm{NO}_{x}$ by hydrolysis of the nitrate group and/or by deposition. Organic nitrates thus act as sinks and reservoirs of $\mathrm{NO}_{x}$, leading to a broader spatial distribution of $\mathrm{NO}_{x}$ and thus spreading the ozone, HONO, and SOA formation from the local to the regional scale. For this reason, understanding and considering the reactivity of organic nitrates is necessary for accurately predicting their atmospheric fates and impacts on air quality.

The gas-phase chemistry of organic nitrates has been studied through kinetic experiments focusing on their $\cdot \mathrm{OH}$ oxidation (Bedjanian et al., 2018; Picquet-Varrault et al., 2020; Treves and Rudich, 2003; Wängberg et al., 1996; Zhu et al., 1991) and direct photolysis (Clemitshaw et al., 1997; Picquet-Varrault et al., 2020; Suarez-Bertoa et al., 2012). These experiments provide data for different types of organic nitrates, including alkyl nitrates, ketonitrates, hydroxy nitrates, dinitrates, cyclonitrates, and alkene nitrates, and provide knowledge on their gas-phase atmospheric fate. Although alkyl and alkene nitrates are highly volatile, polyfunctional organic nitrates may show much lower volatility and they can partition to condensed phases as aqueous and aerosol phases. Their presence in submicron particles has been observed in a fraction ranging from 5\% to $77 \%$ (in mass) of organic aerosol in Europe and North America (Kiendler-Scharr et al., 2016; Lee et al., 2019). Despite this fact, their reactivities in condensed phases have been poorly explored. Most studies have focused on hydrolysis, a reaction that is extremely structure dependent, mostly occurring in tertiary or allylic nitrates (Hu et al., 2011; Liu et al., 2012), while the non-hydrolyzable fraction of $\alpha$ - and $\beta$ pinene particulate organic nitrate ranges from $68 \%$ to $91 \%$ in mass (Takeuchi and Ng, 2019). To our knowledge, only one study experimentally determined the photolysis kinetics of organic nitrates in the aqueous phase (Romonosky et al., 2015) and concluded that the $\cdot \mathrm{OH}$ removal processes should have a higher relevance. However, there have been no attempts to experimentally determine their aqueous-phase -OH-oxidation reactivity.

Aqueous-phase $\cdot \mathrm{OH}$-oxidation processes play a key role in the removal and production of water-soluble compounds in the atmosphere (Herrmann et al., 2015). The determination of kinetic rate constants is essential to understand their lifetimes and to develop more precise models to predict pollution events and the scale of pollutant transport. Determining aqueous-phase $\cdot \mathrm{OH}$-oxidation second-order rate constants $\left(k_{\mathrm{OH}}\right)$ may be done by competition kinetic methods consisting of a comparison between the decay of the target compound versus a reference compound, for which the $k_{\mathrm{OH}}$ value is well known. Many studies have used the thiocyanate anion $\left(\mathrm{SCN}^{-}\right)$as the reference compound. Its decay can be easily followed by online spectroscopic measurement of the formed radical anion $(\mathrm{SCN})_{2}{ }^{-}$in the presence and absence of the target compound (Herrmann, 2003). This technique, however, is not well suited for species with low reactivity for which $k_{\mathrm{OH}} \leq 10^{9} \mathrm{~L} \mathrm{~mol}^{-1} \mathrm{~s}^{-1}$, i.e., more than 10 times lower than $k_{\mathrm{OH}+\mathrm{SCN}}=1.12( \pm 0.20) \times 10^{10} \mathrm{~L} \mathrm{~mol}^{-1} \mathrm{~s}^{-1}$. In this case, the target species should reach high concentrations to be able to compete with the thiocyanate anion. These high concentrations may interfere with the measurements. Other indirect methods use offline measurements for monitoring the target and reference compounds. However, most of these methods use reference compounds for which $k_{\mathrm{OH}}$ values have not been so widely explored, thus inducing important uncertainties in the experimentally determined $k_{\mathrm{OH}}$ values (Herrmann, 2003).

The aim of this work was to accurately determine aqueousphase $k_{\mathrm{OH}}$ rate constants by developing a new online competition kinetic method, which is well suited to species with low reactivity. The effectiveness and the relevance of the method were validated on compounds for which $k_{\mathrm{OH}}$ rate constants are well known. Then, the method was used to determine the $k_{\mathrm{OH}}$ rate constants of some organic nitrates, and the results were used to extend the aqueous-phase structure-activity relationship (SAR) developed earlier (Monod and Doussin, 2008; Doussin and Monod, 2013) to the nitrate group. Furthermore, the prediction of $k_{\mathrm{OH}}$ rate constants for other atmospherically relevant organic nitrates in the aqueous phase was performed with the extended SAR. Finally, the potential multiphase fate of these compounds in the atmosphere was estimated.

\section{Experimental}

\subsection{Principle}

The originality of this work relies on a competition kinetic method monitored by online decay measurements of the reference compound in the reactor's headspace using a proton transfer reaction mass spectrometer (PTR-MS). Concerning the target compounds, depending on their properties (solubility, volatility, and instrumental response), their kinetic decays were monitored in the reactor's headspace by PTRMS or offline by ultra-high-performance liquid chromatography photodiode array detector (UHPLC-UV). The developed method employed methanol as the reference compound because (i) its $k_{\mathrm{OH}}$ rate constant, $9.7( \pm 1.5) \times 10^{8} \mathrm{~L} \mathrm{~mol}^{-1} \mathrm{~s}^{-1}$ at $298 \mathrm{~K}$, is widely accepted (Table S1); (ii) this value is relevant for competitive kinetics relative to species with low reactivity; and (iii) its extremely sensitive quantification by PTR-MS was expected to not suffer from any interfer- 
ences with the selected organic nitrates (Aoki et al., 2007; Lindinger et al., 1998).

Due to the known sensitivity of organic nitrates to photolysis (Romonosky et al., 2015), aqueous • OH radicals were generated in the dark by the Fenton reaction (Reaction R1) (Neyens and Baeyens, 2003) by dropwise addition of a solution of $\mathrm{Fe}^{2+}$ to an acidic solution of $\mathrm{H}_{2} \mathrm{O}_{2}$ in excess containing methanol and the target compound.

$\mathrm{Fe}^{2+}+\mathrm{H}_{2} \mathrm{O}_{2} \rightarrow \mathrm{Fe}^{3+}+\cdot \mathrm{OH}+\mathrm{OH}^{-}$

The method was validated using isopropanol and acetone as target compounds, whose $\cdot \mathrm{OH}$-oxidation rate constants are well known (Table S1). The method was then used to determine new $k_{\mathrm{OH}}$ values for four alkyl nitrates (isopropyl nitrate, isobutyl nitrate, 1-pentyl nitrate, and isopentyl nitrate) and three polyfunctional organic nitrates ( $\alpha$-nitrooxyacetone, 1 nitrooxy-2-propanol, and isosorbide 5-mononitrate); see Table 1. Furthermore, a tentative study of 2-ethylhexyl nitrate $k_{\mathrm{OH}}$ rate constant was performed using this method, but it was limited by its very low solubility.

\subsection{Experimental setup and protocol}

The aqueous-phase reactor consisted of a $1 \mathrm{~L}$ three-neck round-bottom flask closed hermetically with rubber caps (Fig. 1). A Razel syringe pump at $0.33 \mathrm{~mL} \mathrm{~min}^{-1}$ was used with a glass syringe to add dropwise a solution of $\mathrm{Fe}^{2+}$ into the reactor's aqueous solution. A second syringe was also connected to the reactor to add the target and the reference compounds and to sample the aqueous phase when necessary. The reactor's aqueous solution was continuously stirred before and during the reaction with a magnetic stirrer. A flow of synthetic air constantly guided a fraction of the headspace gas phase to the PTR-MS instrument, with a flow of $0.050 \mathrm{~L} \mathrm{~min}^{-1}$ using a mass flow controller (Brooks SLA Series). A 1:30 dilution was performed downward of the reactor's flow using synthetic air at $1.450 \mathrm{~L} \mathrm{~min}^{-1}$. All experiments were performed at room temperature $(296 \pm 2 \mathrm{~K})$.

In each experiment, the $\mathrm{Fe}^{2+}$ solution consisted of 5$10 \mathrm{~mL}$ of $\mathrm{FeSO}_{4} \cdot 7 \mathrm{H}_{2} \mathrm{O}\left(0.02-0.06 \mathrm{~mol} \mathrm{~L}^{-1}\right)$, added dropwise to the solution of $400 \mathrm{~mL}$ of $\mathrm{H}_{2} \mathrm{O}_{2}$ (in excess, i.e., $\left.0.004 \mathrm{~mol} \mathrm{~L}^{-1}\right)$ acidified by $\mathrm{H}_{2} \mathrm{SO}_{4}\left(0.005 \mathrm{~mol} \mathrm{~L}^{-1}\right)$, to keep $\mathrm{pH}=2.5$ (Micro $\mathrm{pH}$ electrode, Thermo) during the reaction. Concentrations and volumes of the $\mathrm{Fe}^{2+}$ solution were varied in order to optimize the $\cdot \mathrm{OH}$ attack on the reference and the target compounds. All experiments and their initial conditions are compiled in Table $\mathrm{S} 2$. The $\mathrm{Fe}^{2+}$ solution was used as the limiting reagent to minimize its possible interference with the organic nitrate reaction products. In addition, it was verified in control experiments that $\mathrm{H}_{2} \mathrm{O}_{2}$, used in excess, did not react with any of the target compounds. Furthermore, control experiments at $\mathrm{pH}=2.5$ confirmed that none of the organic nitrates underwent hydrolysis at significant rates under our experimental conditions.
Prior to each experiment, the reactor's headspace was extensively purged with pure air for $1 \mathrm{~h}$ while PTR-MS measurements were set for stabilization purposes. The target compound and methanol were then added directly into the aqueous phase, and the reactor's headspace signal was monitored for $30 \mathrm{~min}$ before the reaction with constant stirring of the solution to determine the first-order rate constant of evaporation $\left(k_{\mathrm{vap}}\right)$ of each compound under the reaction conditions. The reaction was then started by adding dropwise the $\mathrm{Fe}^{2+}$ solution for 15 to $30 \mathrm{~min}$ (depending on the volume of $\mathrm{Fe}^{2+}$ added). During experiments performed with isopropyl nitrate, $\alpha$-nitrooxyacetone, 1-nitrooxy-2-propanol, and isosorbide 5-mononitrate, the aqueous phase was sampled every $3 \mathrm{~min}$ for offline measurements by UHPLC-UV. Once the flow of $\mathrm{Fe}^{2+}$ was stopped, the system was kept stirring for another $30 \mathrm{~min}$ while continuously monitoring the reactor's headspace.

\subsection{Methodology}

In such a competition between the target compound $(\mathrm{X})$ and methanol (M) towards $\cdot \mathrm{OH}$ radicals (Reaction $\mathrm{R} 2$ ),

$\mathrm{X} / \mathrm{M}+\cdot \mathrm{OH} \rightarrow$ Products,

in the absence of direct photolysis, the second-order kinetic rate constant of the target compound, $k_{\mathrm{OH}, \mathrm{X}}\left(\mathrm{in} \mathrm{L} \mathrm{mol}{ }^{-1} \mathrm{~s}^{-1}\right.$ ), is directly obtained from the slope $\left(k_{\mathrm{OH}, \mathrm{X}} / k_{\mathrm{OH}, \mathrm{M}}\right)$ of the linear plot of $\ln \left([\mathrm{X}]_{0 \text { (aq) }} /[\mathrm{X}]_{t(\mathrm{aq})}\right)$ versus $\ln \left([\mathrm{M}]_{0 \text { (aq) }} /[\mathrm{M}]_{t(\mathrm{aq})}\right)$ derived from Eq. (1).

$\ln \frac{[\mathrm{X}]_{0(\mathrm{aq})}}{[\mathrm{X}]_{t(\mathrm{aq})}}=\frac{k_{\mathrm{OH}, \mathrm{X}}}{k_{\mathrm{OH}, \mathrm{M}}} \cdot \ln \frac{[\mathrm{M}]_{0(\mathrm{aq})}}{[\mathrm{M}]_{t(\mathrm{aq})}}$,

where $[\mathrm{X}]_{0(\mathrm{aq})} /[\mathrm{X}]_{t(\mathrm{aq})}$ represents the aqueous-phase concentration relative decay of the target compound, and $[\mathrm{M}]_{0(\mathrm{aq})} /[\mathrm{M}]_{t(\mathrm{aq})}$ represents the aqueous-phase concentration relative decay of methanol.

Using the Fenton Reaction (R1), $\cdot \mathrm{OH}$ radicals were generated within the aqueous phase and could not reach the headspace in sufficient numbers to react significantly with the target compounds in the gas phase. This was confirmed by the validation experiments (Sect. 3.1) where the values found for $k_{\mathrm{OH}, \mathrm{X}} / k_{\mathrm{OH}, \mathrm{M}}$ ratios were those of the aqueousphase reactions and not those of the gas phase, which are a factor of 2 to 3 higher.

Headspace analyses were based on the direct proportionality between aqueous- and gas-phase concentrations of the analytes (Karl et al., 2003). Therefore, in cases where both the target and the reference compounds were monitored by PTR-MS, Eq. (1) can be written as Eq. (2) (see Appendix A for detailed explanations).

$\ln \frac{\mathrm{ncps}(\mathrm{X})_{0}}{\mathrm{ncps}(\mathrm{X})_{t}}=\frac{k_{\mathrm{OH}, \mathrm{X}}}{k_{\mathrm{OH}, \mathrm{M}}} \cdot \ln \frac{\mathrm{ncps}(\mathrm{M})_{0}}{\mathrm{ncps}(\mathrm{M})_{t}}$,

where $n c p s(X)$ and $n c p s(M)$ are the normalized count rates of the target compound and methanol, respectively; i.e., $\quad \operatorname{ncps}(\mathrm{X})=\sum \operatorname{cps}\left(\mathrm{X}^{+}\right) / \operatorname{cps}\left(\mathrm{H}_{3} \mathrm{O}^{+}\right) \quad$ and 
Table 1. Chemical structures and properties of the studied organic nitrates. Henry's law constants were obtained from Sander (2015) except for 2-ethylhexyl nitrate and isosorbide 5-mononitrate, which were calculated using the SAR developed by Raventos-Duran et al. (2010). Organic nitrate solubilities were calculated using the model WSKOWWINTM.

\begin{tabular}{|c|c|c|c|c|}
\hline Name & Structure & $K_{\mathrm{H}, 298 \mathrm{~K}}\left(\mathrm{~mol} \mathrm{~L}^{-1} \mathrm{~atm}^{-1}\right)$ & Solubility at $298 \mathrm{~K}\left(\mathrm{~mol} \mathrm{~L}^{-1}\right)$ & Monitored by \\
\hline Isopropyl nitrate & & 0.75 & $2.5 \times 10^{-2}$ & PTR-MS, UHPLC-UV \\
\hline Isobutyl nitrate & & 0.60 & $9.4 \times 10^{-3}$ & PTR-MS \\
\hline 1-Pentyl nitrate & & 0.74 & $2.7 \times 10^{-3}$ & PTR-MS \\
\hline Isopentyl nitrate & & 0.40 & $2.5 \times 10^{-3}$ & PTR-MS \\
\hline 2-Ethylhexyl nitrate & & 0.18 & $1 \times 10^{-4}$ & PTR-MS \\
\hline$\alpha$-Nitrooxyacetone & & $1.0 \times 10^{3}$ & 1.6 & UHPLC-UV \\
\hline 1-Nitrooxy-2-propanol & & $6.7 \times 10^{4}$ & 0.6 & UHPLC-UV \\
\hline Isosorbide 5-mononitrate & & $1.3 \times 10^{7}$ & 0.3 & UHPLC-UV \\
\hline Isopropanol & & 130 & 16.6 & PTR-MS \\
\hline Acetone & & 30 & 17.2 & PTR-MS \\
\hline
\end{tabular}

$\mathrm{ncps}(\mathrm{M})=\sum \operatorname{cps}\left(\mathrm{M}^{+}\right) / \operatorname{cps}\left(\mathrm{H}_{3} \mathrm{O}^{+}\right)$. The normalization of the $\mathrm{H}_{3} \mathrm{O}^{+}$count rate removes any signal variability due to fluctuating performance of the ion source.

Depending on the properties of the investigated organic nitrates (i.e., their water solubility, volatility, and instrumental response), different treatments were applied to determine their kinetic decays. All the very volatile compounds were monitored in the reactor's headspace by PTR-MS: this comprised the target alkyl nitrates (for which Henry's law constant $\left.K_{\mathrm{H}}<1 \mathrm{~mol} \mathrm{~L}^{-1} \mathrm{~atm}^{-1}\right)$, as well as methanol, acetone, and isopropanol $\left(K_{\mathrm{H}}<300 \mathrm{~mol} \mathrm{~L}^{-1} \mathrm{~atm}^{-1}\right)$. Furthermore, due to the low water solubility of alkyl nitrates, their initial concentrations were limited to $5 \times 10^{-5} \mathrm{~mol} \mathrm{~L}^{-1}$. On the other hand, the target polyfunctionalized organic nitrates were much less volatile $\left(K_{\mathrm{H}}>1000 \mathrm{~mol} \mathrm{~L}^{-1} \mathrm{~atm}^{-1}\right)$, and their detection by PTR-MS was more problematic; their relative decays were monitored in the aqueous phase by offline UHPLC-UV. For these compounds, the determination of the aqueous-phase $\cdot \mathrm{OH}$-oxidation rate constant was performed by plotting the relative decay of the aqueous-phase concentration $\left(\ln \left([\mathrm{X}]_{0(\mathrm{aq})} /[\mathrm{X}]_{t(\mathrm{aq})}\right)\right.$ against the relative decay of the reference compound signal in the gas phase $\left(\ln \left(\mathrm{ncps}(\mathrm{M})_{0} / \mathrm{ncps}(\mathrm{M})_{t}\right)\right.$ as shown in Eq. (3):

$\ln \frac{[\mathrm{X}]_{0(\mathrm{aq})}}{[\mathrm{X}]_{t(\mathrm{aq})}}=\frac{k_{\mathrm{OH}, \mathrm{X}}}{k_{\mathrm{OH}, \mathrm{M}}} \cdot \ln \frac{\mathrm{ncps}(\mathrm{M})_{0}}{\mathrm{ncps}(\mathrm{M})_{t}}$.

In addition, for the most volatile molecules (i.e., alkyl nitrates), further corrections were performed to subtract the contribution of evaporation to the overall reaction decay. Their high volatilities induced a substantial decay in their concentrations that was systematically measured prior to the start of the reaction, inferring a specific first-order rate constant of evaporation $\left(k_{\mathrm{vap}}\right)$ of each compound under the reaction conditions. While for methanol, acetone, or isopropanol the evaporation decay was negligible, for the alkyl nitrates it accounted for $2 \%$ to $20 \%$ of the molecule's consumption 


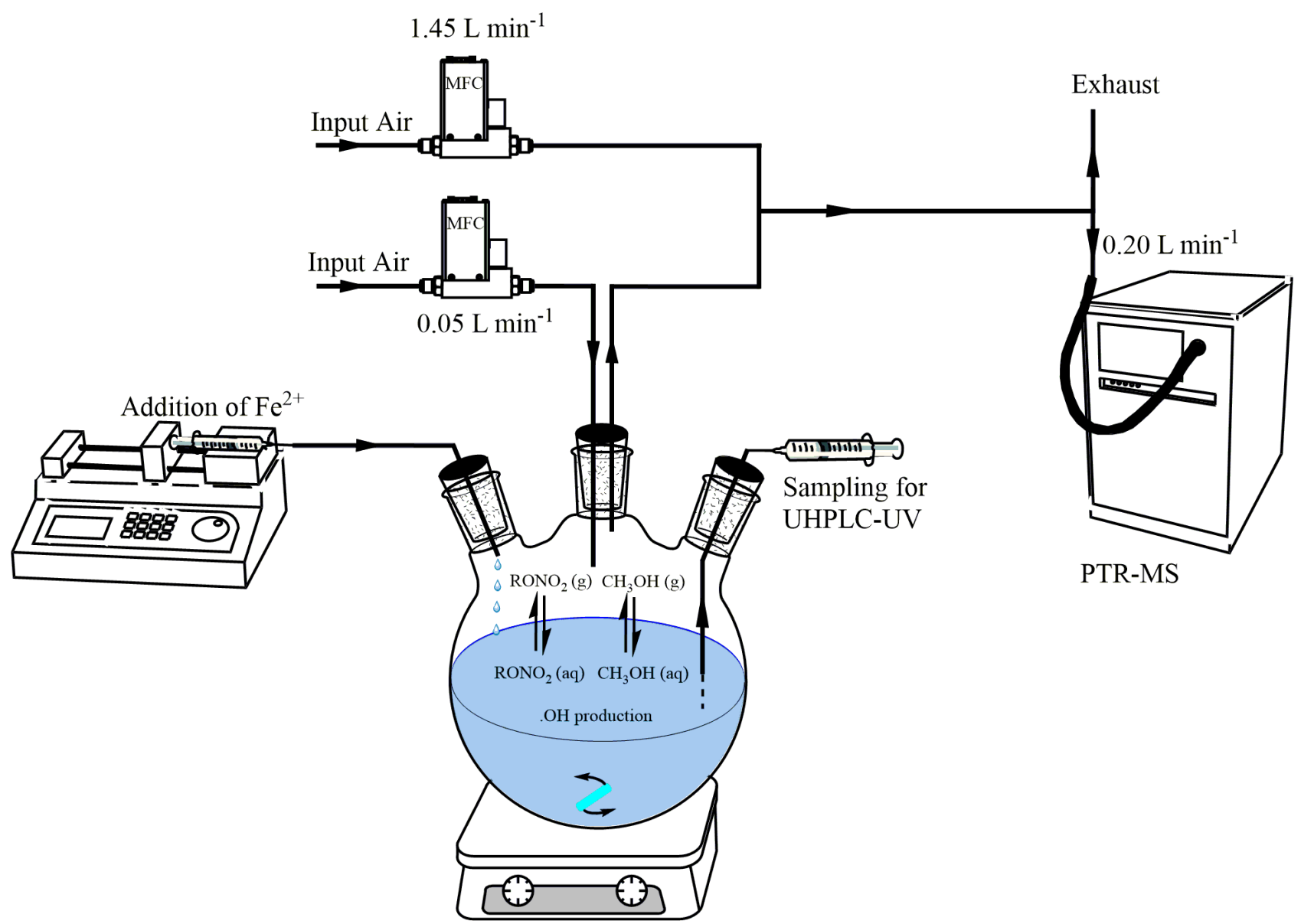

Figure 1. Experimental setup for the competition kinetics method.

during the reaction. To consider this contribution, Eq. (4) was used instead of Eq. (2) for volatile alkyl nitrates:

$\frac{1}{t} \cdot \ln \frac{\operatorname{ncps}(\mathrm{X})_{0}}{\operatorname{ncps}(\mathrm{X})_{t}}=k_{\mathrm{vap}}+\frac{k_{\mathrm{OH}, \mathrm{X}}}{k_{\mathrm{OH}, \mathrm{M}}} \cdot \frac{1}{t} \cdot \ln \frac{\operatorname{ncps}(\mathrm{M})_{0}}{\operatorname{ncps}(\mathrm{M})_{t}}$

where $t$ is the reaction time (in seconds). Plotting $1 / t$. $\ln \left(\operatorname{ncps}(\mathrm{X})_{0} / \operatorname{ncps}(\mathrm{X})_{t}\right)$ versus $1 / t \cdot \ln \left(\operatorname{ncps}(\mathrm{M})_{0} / \operatorname{ncps}(\mathrm{M})_{t}\right)$ resulted in a straight line with a slope of $k_{\mathrm{OH}, \mathrm{X}} / k_{\mathrm{OH}, \mathrm{M}}$ and an intercept of $k_{\text {vap }}$. The value of $k_{\text {vap }}$ was determined during the 30 min prior to the reaction, and its value was fixed in Eq. (4). This treatment was not necessary for methanol, acetone, or isopropanol, due to their lower volatilities. For isopropyl nitrate, whose decay was also monitored in the aqueous phase by UHPLC-UV, Eq. (5) was used (in addition to Eq. 4):

$\frac{1}{t} \cdot \ln \frac{[\mathrm{X}]_{0(\mathrm{aq})}}{[\mathrm{X}]_{t(\mathrm{aq})}}=k_{\mathrm{vap}}+\frac{k_{\mathrm{OH}, \mathrm{X}}}{k_{\mathrm{OH}, \mathrm{M}}} \cdot \frac{1}{t} \cdot \ln \frac{\operatorname{ncps}(\mathrm{M})_{0}}{\operatorname{ncps}(\mathrm{M})_{t}}$.

In summary, the aqueous-phase $\cdot \mathrm{OH}$-oxidation rate constants of isopropanol and acetone were determined using Eq. (2), while Eq. (3) was used for determining the rate constants of $\alpha$-nitrooxyacetone, 1-nitrooxy-2-propanol, and isosorbide 5-mononitrate. For isobutyl nitrate, 1-pentyl nitrate, and isopentyl nitrate, compounds which undergo a significant evaporation decay, Eq. (4) was used. Finally, isopropyl nitrate was chosen for intercomparing both methods as it is water soluble and volatile enough to be monitored by both analytical techniques; its aqueous-phase $k_{\mathrm{OH}}$ was determined by both Eqs. (4) and (5).

\subsection{Analytical measurements}

\subsubsection{PTR-MS}

A commercial high-sensitivity quadrupole PTR-MS (IONI$\mathrm{CON}$ Analytik $\mathrm{GmbH}$ ) was used to monitor the concentration decay of the reference compound (methanol) and seven target compounds (acetone, isopropanol, isopropyl nitrate, isobutyl nitrate, 1-pentyl nitrate, isopentyl nitrate, and 2ethylhexyl nitrate) during the reaction. The drift tube voltage was $600 \mathrm{~V}$, the reactor chamber pressure was $2.19 \mathrm{mbar}$, and the drift tube temperature was $333 \mathrm{~K}$. These values correspond to an $E / N$ value of $136 \mathrm{Td}$ (Townsend, with 1 $\mathrm{Td}=10^{-17} \mathrm{~V} \mathrm{~cm}^{-2}$ ), where $E$ is the electric field strength $\left(\mathrm{V} \mathrm{cm}^{-1}\right)$, and $N$ is the ambient air number density within the 
drift tube (molecule $\mathrm{cm}^{-3}$ ). Measurements were performed using the multiple ion detection (MID) mode on a short list of 11-13 preselected $\mathrm{m} / \mathrm{z}$ values resulting in measurement cycles of $25-35 \mathrm{~s}$. This list includes the hydronium ion isotope $\mathrm{H}_{3}^{18} \mathrm{O}^{+}(m / z=21)$ and its water clusters, $\mathrm{H}_{2} \mathrm{O} \cdot \mathrm{H}_{3} \mathrm{O}^{+}$ and $\left(\mathrm{H}_{2} \mathrm{O}\right)_{2} \cdot \mathrm{H}_{3} \mathrm{O}^{+}(m / z=37$ and $m / z=55$, respectively) as well as parasitic ions $\mathrm{NO}^{+}$and $\mathrm{O}_{2}^{+}(\mathrm{m} / z=30$ and $m / z=$ 32 ) for diagnostic purposes. The remaining ions correspond to the protonated reference compound, methanol $(\mathrm{m} / \mathrm{z}=33)$, and to the 5-7 major products of organic nitrates. The individual fragmentation patterns of the organic nitrates determined during a series of preliminary measurements in scan mode (21-200 amu) are listed in Table S3. Data were corrected by normalizing the ion signals with the number of hydronium ions in the drift tube, calculated by multiplying by 500 the signal at $m / z=21$.

Isopentyl nitrate and 2-ethylhexyl nitrate were analyzed by PTR-MS for the first time. The other compounds, isopropyl nitrate, isobutyl nitrate, and 1-pentyl nitrate, were previously investigated by Duncianu et al. (2017) and Aoki et al. (2007). Table S3 compiles detected fragments and their relative intensities for all the studied organic nitrates in this work. Compared to the previous studies, similar trends in the fragmentation of organic nitrates were found. Fragments with the highest relative intensities correspond to the $\mathrm{R}^{+}$fragment, produced after the nitrate group loss in the drift tube, and to the $\mathrm{NO}_{2}^{+}$ion, which was detected for all organic nitrates, except for 2-ethylhexyl nitrate. Other relevant fragments were the $\mathrm{RO}^{+}$fragment and/or other ions (such as $\mathrm{C}_{3} \mathrm{H}_{5}^{+}, \mathrm{C}_{3} \mathrm{H}_{7}^{+}$, $\mathrm{C}_{4} \mathrm{H}_{9}^{+}$) which were formed by further fragmentation of the $\mathrm{R}^{+}$fragment.

The minimum standard sensitivity normalized to $10^{6}$ hydronium ions for all organic nitrates was determined prior to the start of the reaction, by calculating the maximum possible gas-phase concentrations assuming the Henry's law equilibrium (see Table S3). The sensitivities range from 3 to $7 \mathrm{ncps} \mathrm{ppbv}^{-1}$ for all organic nitrates. From these sensitivities, it was calculated that in the reactor's headspace the target organic nitrates were detectable at concentrations higher than $1 \times 10^{-7} \mathrm{~mol} \mathrm{~L}^{-1}$ in the aqueous phase.

For methanol, assuming Henry's law equilibrium, using a $K_{\mathrm{H}}=204 \mathrm{~mol} \mathrm{~L}^{-1} \mathrm{~atm}^{-1}$ (average value out of those reported in Sander, 2015), the minimum standard sensitivity normalized to $10^{6}$ hydronium ions would be $9 \pm$ $1 \mathrm{ncps} \mathrm{ppbv}^{-1}$, corresponding to an effective sensitivity > $360 \mathrm{cps} \mathrm{ppbv}^{-1}$ at the typical $\mathrm{H}_{3} \mathrm{O}^{+}$count rate of $4 \times 10^{7} \mathrm{cps}$. Under these conditions, it would be detectable in the reactor's headspace at aqueous concentrations higher than $9 \times$ $10^{-6} \mathrm{~mol} \mathrm{~L}^{-1}$.

\subsubsection{UHPLC-UV}

All the investigated organic nitrates show an intense UV absorption around $200 \mathrm{~nm}$ (Fig. S1). Aliquots of the solution were sampled every $3 \mathrm{~min}$ from the reactor and the least volatile target compounds were quantified by UHPLC-UV (Thermo Scientific Accela 600) at $200 \mathrm{~nm}$. The device was equipped with a Hypersil Gold C18 column $(50 \times 2.1 \mathrm{~mm})$ with a particle size of $1.9 \mu \mathrm{m}$ and an injection loop of $5 \mu \mathrm{L}$. A binary eluent of $\mathrm{H}_{2} \mathrm{O}$ and $\mathrm{CH}_{3} \mathrm{CN}$ was used for all analyses at a flow rate of $400 \mu \mathrm{Lmin}^{-1}$. Two gradients were used depending on the compounds' polarity. For isopropyl nitrate, the gradient started from $\mathrm{H}_{2} \mathrm{O} / \mathrm{CH}_{3} \mathrm{CN} 80 / 20(v / v)$ to $50 / 50(v / v)$ for $3 \mathrm{~min}$, held at this proportion for $1 \mathrm{~min}$, and then set back to $80 / 20(v / v)$ within 10 s until the end of the run, at minute 5 (method A). For more polar compounds, i.e., $\alpha$-nitrooxyacetone, 1-nitrooxy-2-propanol, and isosorbide 5-mononitrate, a similar gradient was employed but the initial and final proportions were $\mathrm{H}_{2} \mathrm{O} / \mathrm{CH}_{3} \mathrm{CN} 90 / 10$ $(v / v)$ in order to optimize their retention times $(\operatorname{method} \mathrm{B})$.

Calibration curves were optimized to obtain good linearity between $5 \times 10^{-5}$ and $1 \times 10^{-3} \mathrm{~mol} \mathrm{~L}^{-1}$ with a $R^{2}>0.9995$. The retention times were $0.9,1.1,1.2$, and 2.4 min for 1-nitrooxy-2-propanol, isosorbide 5-mononitrate, $\alpha$-nitrooxyacetone, and isopropyl nitrate, respectively. Limits of detection are $9 \times 10^{-6} \mathrm{~mol} \mathrm{~L}^{-1}$ for isopropyl nitrate and $1 \times 10^{-5} \mathrm{~mol} \mathrm{~L}^{-1}$ for the other three compounds.

\subsection{Reagents}

Chemicals were commercially available and used as supplied: isopropyl nitrate (96\%, Sigma-Aldrich), isobutyl nitrate (98\%, Sigma-Aldrich), 2-ethylhexyl nitrate (97\%, Sigma-Aldrich), 1-pentyl nitrate (98\%, TCI Chemicals), isopentyl nitrate (98\%, TCI Chemicals), isosorbide 5mononitrate (98\%, Acros Organics), $\mathrm{H}_{2} \mathrm{O}_{2}$ (30\%, nonstabilized, Acros Organics), $\mathrm{FeSO}_{4} \cdot 7 \mathrm{H}_{2} \mathrm{O}$ (99\%, SigmaAldrich), $\mathrm{H}_{2} \mathrm{SO}_{4}$ (95\%-98\%, Merck), chloroacetone (95\%, Sigma-Aldrich), $\mathrm{AgNO}_{3}$ (99\%, VWR Chemicals), KI ( $98 \%$, Sigma-Aldrich), and $\mathrm{NaBH}_{4}$ (98\%, Sigma-Aldrich). Methanol (Fisher Chemical), acetonitrile (Fisher Optima), and isopropanol (Honeywell) were LC/MS grade and used as supplied. Acetone (Carlo Erba Reagents) and ether (Fisher Chemical) were HPLC grade. Tap water was purified with a Millipore Milli-Q system $(18.2 \mathrm{M} \Omega \mathrm{cm}$ and TOC $<2 \mathrm{ppb})$.

Non-commercial organic nitrates, i.e., $\alpha$-nitrooxyacetone and 1-nitrooxy-2-propanol, were synthesized and purified. $\alpha$-Nitrooxyacetone was synthesized by the nucleophilic substitution reaction of iodoacetone which was synthesized previously from chloroacetone. The ketone group from $\alpha$-nitrooxyacetone was reduced to produce 1-nitrooxy-2propanol. See Sect. S1 in the Supplement for further details.

\section{Results and discussion}

\subsection{Validation of the kinetic method}

Three different kinds of validation experiments were performed. Their goals were (1) to verify that the partition of the reactants between the aqueous phase and the gas phase (in the 
reactor's headspace) was rapidly reached during the reaction; (2) to intercompare the two methods (PTR-MS and UHPLC$\mathrm{UV})$; and (3) to validate the aqueous-phase kinetic $k_{\mathrm{OH}}$ rate constants using well-known values, i.e., those of acetone and isopropanol.

Figure 2a shows the headspace signal measured by PTRMS during the aqueous-phase $\cdot \mathrm{OH}$ oxidation of isopropyl nitrate. The light blue background indicates periods when the solution of $\mathrm{Fe}^{2+}\left(0.06 \mathrm{~mol} \mathrm{~L}^{-1}\right)$ was dripped into the reactor to produce $\cdot \mathrm{OH}$ radicals. One can clearly observe how the isopropyl nitrate signal decay starts immediately at the beginning of the addition of $\mathrm{Fe}^{2+}$ and ceases promptly when it is stopped. The partition between the aqueous phase and the reactor's headspace is therefore swiftly reached and is faster than the PTR-MS measurement cycle rate ( $25 \mathrm{~s}$ for the shortest cycle).

Figure $2 \mathrm{~b}$ shows the isopropyl nitrate decay during its aqueous-phase $\cdot \mathrm{OH}$-oxidation while monitoring its concentration with the PTR-MS and the UHPLC-UV. It is clear from the figure that the kinetics are identical for both methods. Furthermore, the ratios of $k_{\mathrm{OH} \text {,isopropryl nitrate }} / k_{\mathrm{OH}}$,methanol were $0.29( \pm 0.06)$ and $0.31( \pm 0.06)$ using the PTR-MS method, Eq. (4), and the UHPLC-UV one, Eq. (5), respectively. These results obtained for isopropyl nitrate confirm that its gas-phase concentrations in the reactor's headspace are proportional to its aqueous-phase concentrations. In addition, this proves that there is no $\cdot \mathrm{OH}$ attack in the gas phase: the ratios of $k_{\mathrm{OH}, \mathrm{X}} / k_{\mathrm{OH}, \mathrm{M}}$ observed are significantly different from the gas-phase rate constant ratios, which are about 2 or 3 times higher. Furthermore, it shows that there are no further interferences in the reaction other than the compound evaporation.

The validation of the method was achieved by determining the aqueous-phase $\cdot \mathrm{OH}$-oxidation rate constants for acetone and isopropanol, which have been extensively studied in the literature (Table S1). Both compound decays were monitored in the reactor's headspace with the PTR-MS, and their $k_{\mathrm{OH}}$ values were determined using Eq. (2). The experiments were triplicated. The uncertainty of the rate constant was calculated by the propagation of the standard deviation of the three values and the methanol rate constant uncertainty.

Figure 3 compares the experimentally determined $k_{\mathrm{OH}}$ values for acetone and isopropanol in this work with the previous values reported in the literature. The determined rate constants, $1.9( \pm 0.1) \times 10^{9} \mathrm{~L} \mathrm{~mol}^{-1} \mathrm{~s}^{-1}$ for isopropanol and 1.0 $( \pm 0.2) \times 10^{8} \mathrm{~L} \mathrm{~mol}^{-1} \mathrm{~s}^{-1}$ for acetone, agree very well with the reported values within the experimental uncertainties.

These results show the relevance of the developed method for accurately determining the aqueous-phase $\cdot \mathrm{OH}$-oxidation rate constant of any semivolatile or non-volatile compound detectable either by PTR-MS or by UHPLC-UV. Hereafter, the new rate constants for organic nitrates are presented and discussed.

\subsection{New aqueous-phase $k_{\mathrm{OH}}$ determinations: application of the kinetic method to organic nitrates}

Aqueous-phase $k_{\mathrm{OH}}$ for organic nitrates were determined for the first time using the developed competition method. The kinetic rate constants were calculated by Eq. (4) for isobutyl nitrate, 1-pentyl nitrate, and isopentyl nitrate; by Eq. (3) for $\alpha$-nitrooxyacetone, 1-nitrooxy-2-propanol, and isosorbide 5mononitrate; and by Eqs. (4) and (5) for isopropyl nitrate. Figure 4 shows some examples of the linear regressions obtained for each organic nitrate where the slope corresponds to the $k_{\mathrm{OH}, \mathrm{X}} / k_{\mathrm{OH}, \mathrm{M}}$ ratio. It evidences the diversity of values obtained for the studied organic nitrates, which all fall within less than an order of magnitude from that of methanol, thus confirming that this reference is appropriate for the studied molecules.

The determined aqueous-phase $\cdot \mathrm{OH}$-oxidation rate constants for the organic nitrates are compiled in Table 2. Uncertainties were calculated by propagating the standard deviation of the replicates with the uncertainty of the methanol $k_{\mathrm{OH}}$ rate constant. Then, to account for the small number of experiments performed for some molecules, the uncertainties are given by the confidence limits of $95 \%$ given by Student's $t$ distribution. This explains why the value obtained for 1 pentyl nitrate shows the largest uncertainty as its $k_{\mathrm{OH}}$ was determined by only two experiments. Data for 2-ethylhexyl nitrate showed inconsistency compared to the other alkyl nitrates (significantly lower value with respect to its chemical structure). It is possible that even with a low initial concentration $\left(5 \times 10^{-5} \mathrm{~mol} \mathrm{~L}^{-1}\right)$, well below its solubility threshold $\left(1 \times 10^{-4} \mathrm{~mol} \mathrm{~L}^{-1}\right)$, the complete dissolution of the compound was not achieved when the reaction started, thus inducing an incorrect rate constant value. Furthermore, it is suspected, from its structure, to present some surface activity, thus preventing this compound from dissolving into the bulk water.

Even though there are no other data available in the literature to compare with, the $k_{\mathrm{OH}}$ values obtained for the other organic nitrates are consistent regarding the chemical structures: they reflect that the rate constant increases with the number of reactive sites. In more detail, the chemical structure of the organic nitrate and the position of the nitrate group plays an important role in the $\cdot \mathrm{OH}$-oxidation rate constant. Figure 5a compares these values with the rate constants of their corresponding alcohols and non-functionalized molecules. It shows how the $\cdot \mathrm{OH}$ oxidation is reduced when the nitrate group $\left(-\mathrm{ONO}_{2}\right)$ is replacing an alcohol group $(-\mathrm{OH})$ or hydrogen $(-\mathrm{H})$. The nitrate group attached to a primary carbon atom (i.e., isobutyl nitrate, 1-pentyl nitrate, isopentyl nitrate, $\alpha$-nitrooxyacetone, and 1-nitrooxy2-propanol) slows down the reactivity by a factor of 1.7 to 3.1 in comparison to their $\mathrm{H}$-substituted homologs (isobutane, pentane, isopentane, acetone, and isopropanol). For iso- 
(a)

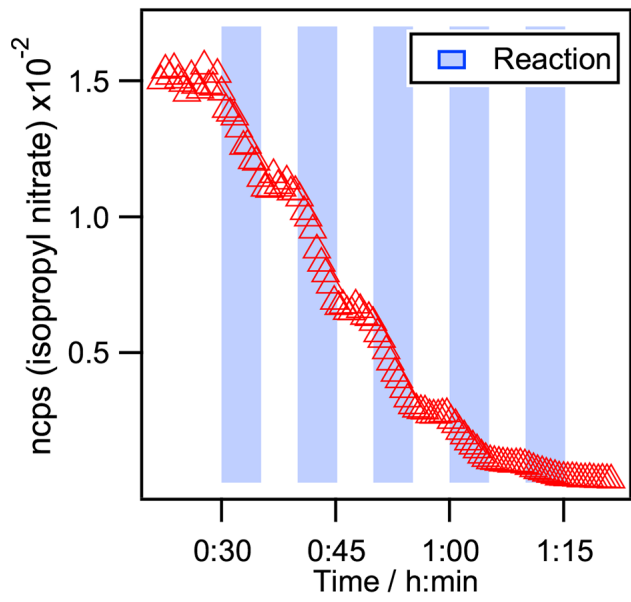

(b)

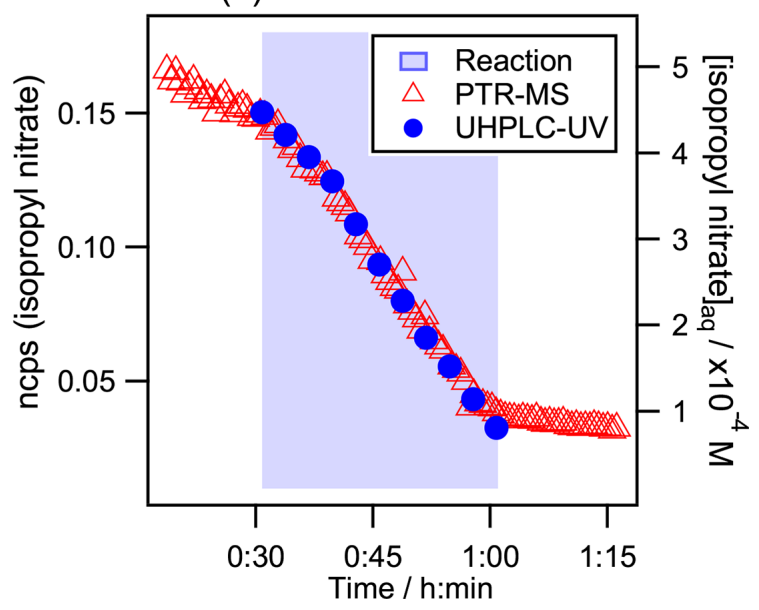

Figure 2. Kinetic decays of isopropyl nitrate during its aqueous-phase $\cdot \mathrm{OH}$ oxidation. (a) Monitored by PTR-MS during several sequential additions of the $\mathrm{Fe}^{2+}$ solution. Initial conditions in the reactor were [Isopropyl nitrate $]_{0}=5 \times 10^{-5} \mathrm{~mol} \mathrm{~L}^{-1},\left[\mathrm{H}_{2} \mathrm{O}_{2}\right]_{0}=4 \times 10^{-3} \mathrm{~mol} \mathrm{~L}^{-1}$, and $\left[\mathrm{H}_{2} \mathrm{SO}_{4}\right]_{0}=5 \times 10^{-3} \mathrm{~mol} \mathrm{~L}^{-1}$. (b) Intercomparison between PTR-MS and UHPLC-UV detection. Initial conditions were [Isopropyl nitrate $]_{0}=6 \times 10^{-4} \mathrm{~mol} \mathrm{~L}^{-1},\left[\mathrm{CH}_{3} \mathrm{OH}\right]_{0}=3 \times 10^{-4} \mathrm{~mol} \mathrm{~L}^{-1},\left[\mathrm{H}_{2} \mathrm{O}_{2}\right]_{0}=4 \times 10^{-3} \mathrm{~mol} \mathrm{~L}^{-1}$, and $\left[\mathrm{H}_{2} \mathrm{SO}_{4}\right]_{0}=5 \times 10^{-3} \mathrm{~mol} \mathrm{~L}^{-1}$. In both graphs, the time is set to 0 when isopropyl nitrate is injected. Blue background indicates periods when the solution of $\mathrm{Fe}^{2+}\left(0.06 \mathrm{~mol} \mathrm{~L}^{-1}\right)$ was dripped into the reactor to produce $\bullet \mathrm{OH}$ radicals.

(a)

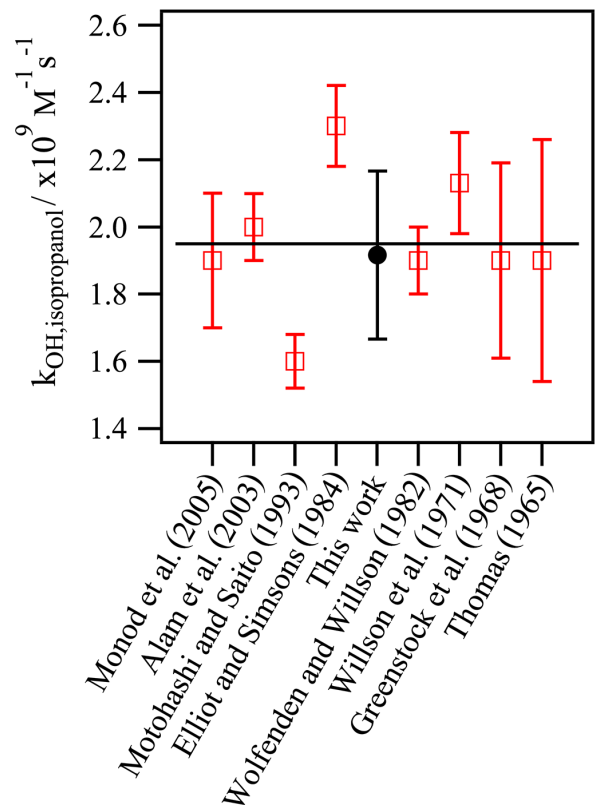

(b)

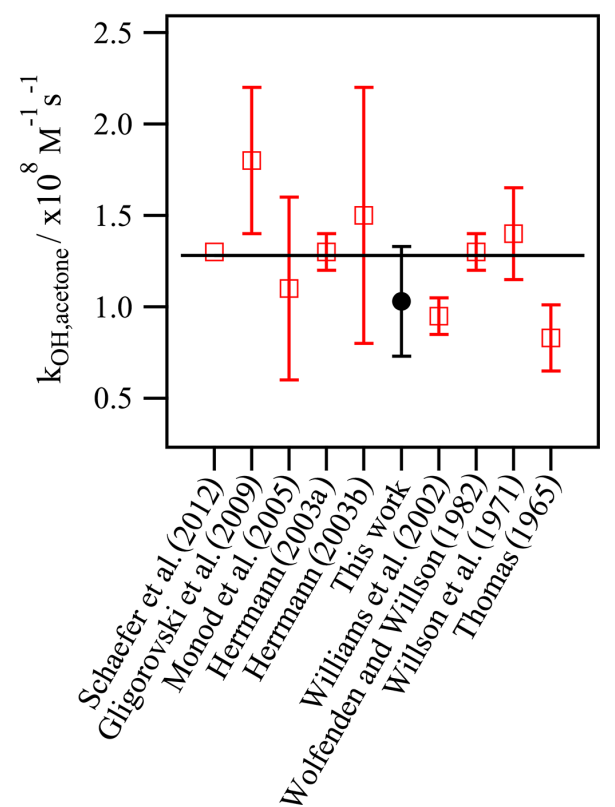

Figure 3. Validation experiments: determination of the aqueous-phase $k_{\mathrm{OH}}$ values using the new developed method and comparison with the reported values in the literature for (a) isopropanol and (b) acetone. The horizontal line represents the average value of the previous studies.

propyl nitrate, a secondary organic nitrate, the $\cdot \mathrm{OH}$ attack is reduced by an order of magnitude compared to $n$-propane.

A reduction of the reactivity caused by the presence of the nitrate group also occurs in the gas phase but in a much slighter manner (Fig. 5b). It has been discussed that the nitrate group has an electron-withdrawing nature that strength- ens the $\mathrm{C}-\mathrm{H}$ bond of the $\alpha$ - and the $\beta$-carbon atoms, thus lowering the hydrogen abstraction (Atkinson et al., 1982). However, the reduction of the reactivity is clearly more pronounced in the aqueous phase, implying a solvent kinetic effect that can more effectively lower the reactivity. This could be induced by the stabilization of the reactant (Koner et al., 
(a)

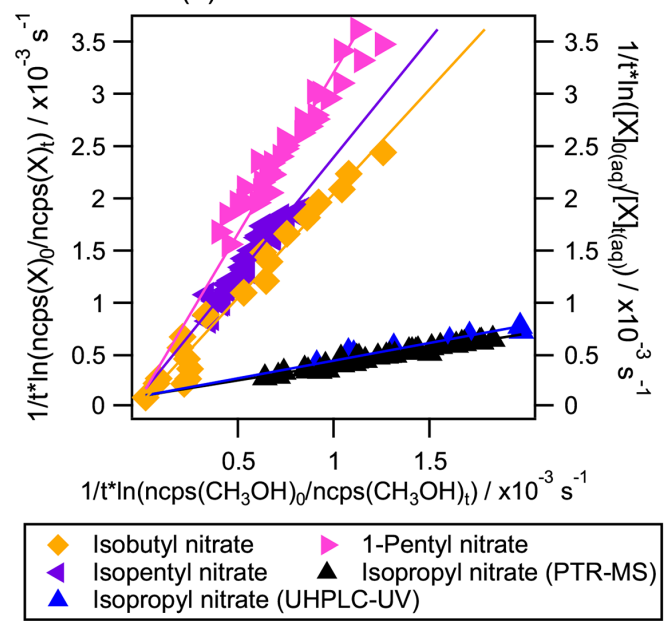

(b)

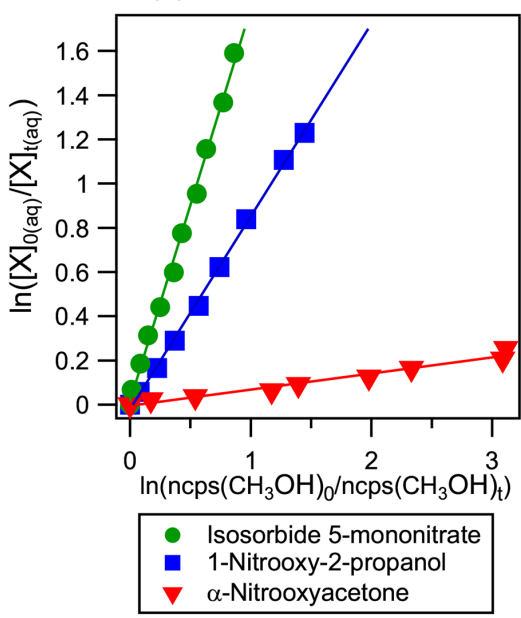

Figure 4. Examples of competition kinetic results for the studied organic nitrates using the new developed method: experiments 8, 14, 16, 19, 21, 24, and 26 (listed in Table S2). In panel (a) molecules were monitored in the reactor's headspace by PTR-MS (left axis and horizontal axis) except for isopropyl nitrate which was also monitored by UHPLC-UV (right axis). In panel (b) methanol was monitored in the reactor's headspace by PTR-MS (horizontal axis) while the polyfunctional organic nitrates were followed by UHPLC-UV (left axis).

Table 2. Aqueous-phase $\cdot \mathrm{OH}$-oxidation rate constants for eight organic nitrates: comparison between the experimental rate constants $\left(k_{\mathrm{OH} \text { exp }}\right)$ and the simulated ones $\left(k_{\mathrm{OH}}\right.$ sim $)$ using the extended SAR. Calculations use the SAR parameters indicated in Table 4 . The factor $\Delta$ is the relative difference between the simulated and the experimental rate constant (Eq. 10). $n$ stands for the number of experimental determinations of each rate constant (note that for isopropyl nitrate six experiments were performed; in three of them the value was determined twice using both Eqs. (4) and (5), thus resulting in nine determinations). Experimental uncertainties are $95 \%$ confidence interval.

\begin{tabular}{lrrrr}
\hline Studied compounds & $k_{\mathrm{OH} \exp }\left(\times 10^{8} \mathrm{~L} \mathrm{~mol}^{-1} \mathrm{~s}^{-1}\right)$ & $k_{\mathrm{OH} \mathrm{sim}}\left(\times 10^{8} \mathrm{~L} \mathrm{~mol}^{-1} \mathrm{~s}^{-1}\right)$ & $\Delta$ & $n$ \\
\hline Isopropyl nitrate & $2.8( \pm 0.6)$ & 3.0 & -0.07 & 9 \\
Isobutyl nitrate & $17( \pm 11)$ & 13.5 & +0.22 & 3 \\
1-Pentyl nitrate & $31( \pm 46)$ & 31.8 & -0.02 & 2 \\
Isopentyl nitrate & $22( \pm 9)$ & 24.6 & -0.10 & 3 \\
$\alpha$-Nitrooxyacetone & $0.8( \pm 0.4)$ & 1.3 & -0.69 & 3 \\
1-Nitrooxy-2-propanol & $8.7( \pm 1.9)$ & 6.3 & +0.28 & 3 \\
Isosorbide 5-mononitrate & $18( \pm 5)$ & 14.2 & +0.19 & 3 \\
\hline
\end{tabular}

2007) or by the formation of a solvent barrier provoked by the nitrate group solvation which could hinder the attack of the hydroxyl radical. The latter inhibiting effect could hinder the $\cdot \mathrm{OH}$ attack further than the $\beta$ position, up to the $\gamma$ position.

In order to evaluate this question and to predict the reactivity of other organic nitrates with $\cdot \mathrm{OH}$ radicals in the aqueous phase, we have investigated a structure-activity relationship (SAR).

\subsection{Structure-activity relationship (SAR) for -OH-oxidation rate constants for organic nitrates}

\subsubsection{SAR principles}

Using the experimentally determined aqueous-phase $\cdot \mathrm{OH}-$ oxidation rate constants, the aqueous-phase SAR previously developed by Monod and Doussin (2008) and Doussin and
Monod (2013) was extended to organic nitrates. Briefly, the principle of the estimation assumes that the overall rate constant for the $\cdot \mathrm{OH}$-radical-induced $\mathrm{H}$ abstraction is equal to the sum of each kinetic rate of each reactive site. These partial kinetic rate constants are determined by considering the chemical environment of the function along the carbon skeleton. Each $-\mathrm{CH}_{3},-\mathrm{CH}_{2}-,-\mathrm{CH}<,-\mathrm{OH}$, and $-\mathrm{CHO}$ function of the molecule is associated with a group kinetic rate constant: $k$ (group). To consider both field and resonance effects, the rate constants $k$ associated with each $\mathrm{H}$-bearing function are modulated with both the $\alpha$-neighboring effect (represented by the F parameters) and the $\beta$-neighboring effect (represented by the $\mathrm{G}$ parameters). This aqueous-phase SAR can predict the $\cdot \mathrm{OH}$-oxidation rate constants of alkanes, alcohols, diols, geminal diols, carbonyls, carboxylic acids, carboxylates, and cyclic compounds as well as polyfunctional molecules. For organic nitrates, in addition to the $\mathrm{F}(-$ 
(a)

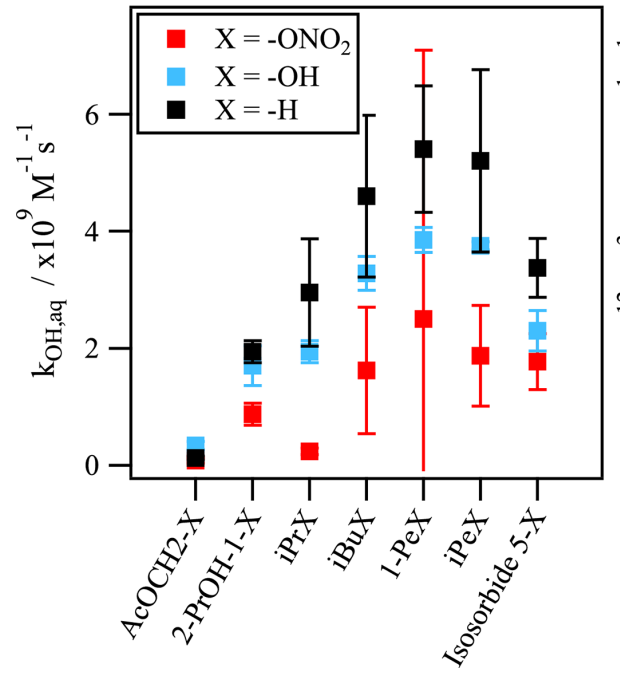

(b)

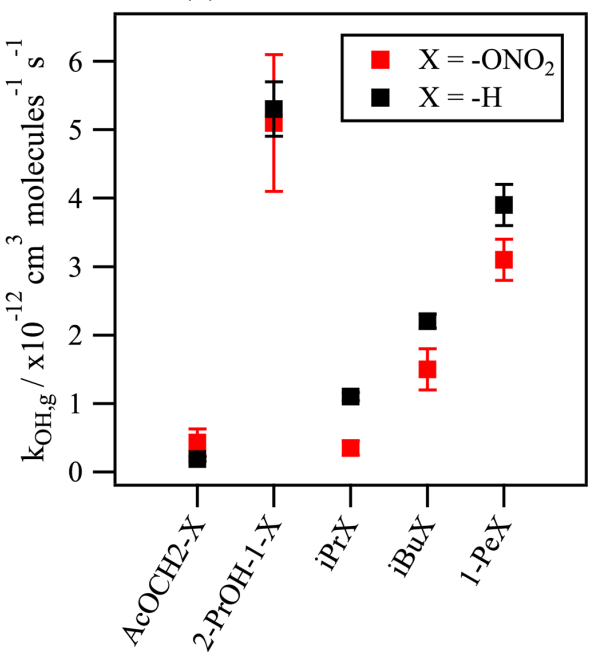

Figure 5. Comparison between the $k_{\mathrm{OH}}$ values for organic nitrates, the corresponding alcohols, and non-substituted homolog compounds (a) in the aqueous phase and (b) in the gas phase. Aqueous-phase $k_{\mathrm{OH}}$ values were taken from Reuvers et al. (1973) and Adams et al. (1965) for alcohols; Getoff (1991) and Rudakov et al. (1981) for H-substituted compounds; and the predictions using the SAR for hydroxy acetone and the $-\mathrm{OH}$ and $-\mathrm{H}$ substituted homologs of isosorbide 5-mononitrate. Gas-phase $k_{\mathrm{OH}}$ values were taken from Atkinson et al. (1982); Atkinson and Aschmann (1989); Becker and Wirtz (1989); Bedjanian et al. (2017); Suarez-Bertoa et al. (2012); Talukdar et al. (1997); Treves and Rudich (2003); and Zhu et al. (1991) for organic nitrates as well as from Atkinson et al. (1997, 1992) and Atkinson (2003) for H-substituted homologs.

$\left.\mathrm{ONO}_{2}\right)$ and $\mathrm{G}\left(-\mathrm{ONO}_{2}\right)$ parameters, one specific parameter, $\mathrm{H}\left(-\mathrm{ONO}_{2}\right)$, was included to test the influence of the nitrate group on the reactivity on distant reactive sites in $\gamma$ position, Eq. (6):

$$
\begin{aligned}
k & =\sum_{i=1}^{n}\left(k(i) \cdot \prod \mathrm{F}(\alpha \text { group }) \cdot \prod \mathrm{G}(\beta \text { group })\right. \\
& \left.\cdot \prod \mathrm{H}_{\mathrm{ONO}_{2}}(\gamma \text { group }) \cdot C(\text { ring })\right)
\end{aligned}
$$

where $k(i)$ is the partial rate constant for a $-\mathrm{CH}<,-\mathrm{CH}_{2}-$ , $-\mathrm{CH}_{3},-\mathrm{CHO}$, or $-\mathrm{OH} ; \Pi \mathrm{F}(\alpha$-group $) \cdot \mathrm{G}(\beta$-group $)$ is the product of all the contribution factors of the different neighboring groups for a reactive site in the $\alpha$ and $\beta$ positions, respectively; $\mathrm{H}_{\mathrm{ONO}_{2}}$ ( $\gamma$-group) is the contribution factor specific of the nitrate function for a reactive site in the $\gamma$ position; and $C$ (ring) is a contribution factor which represent the ring effect strains and only affects reactive positions inside a ring. Detailed examples where Eq. (6) is applied to calculate the organic nitrates aqueous-phase $k_{\mathrm{OH}}$ can be found in Sect. S2.

In order to include in this new extended SAR a complex polyfunctional molecule such as isosorbide 5-mononitrate, which comprises two 5-atom cycloether structures, the neighboring effects of ethers and cycloethers have also been determined, i.e., $\mathrm{F}(-\mathrm{O}-), \mathrm{G}(-\mathrm{O}-)$, and a parameter $\mathrm{X}\left(-\mathrm{O}_{-}\right.$ ) used to calculate the ring effect strains for cycloethers by multiplying the existing $C$ (ring) factor by a $\mathrm{X}(-\mathrm{O}-)$ contribu- tion factor which indicates the presence of one or two oxygen atoms in the ring.

Furthermore, as with all carbonyl compounds, $\alpha$ nitrooxyacetone can be hydrated in water, leading to an equilibrium with its geminal diol form; thus, the equilibrium constant, $K_{\text {hyd }}$, is defined if water activity is considered to be unity by Eq. (7).

$K_{\text {hyd }}=\frac{[\text { gem-diol }]}{\text { [carbonyl }]}$

The reactivity of these partner molecules toward $\cdot \mathrm{OH}$ radicals can be significantly different (Doussin and Monod, 2013), however, the experimental determination only refers to the global rate constant, defined by Eq. (8).

$k_{\text {overall }}=\frac{K_{\text {hyd }} \cdot k_{\text {gem-diol }}+k_{\text {carbonyl }}}{K_{\text {hyd }}+1}$,

where $k_{\text {overall }}$ is the overall rate constant for the $\cdot \mathrm{OH}$ oxidation, and $k_{\text {gem-diol }}$ and $k_{\text {carbonyl }}$ are the calculated rate constants for the related species. When performing the SAR calculation, this equilibrium was considered, and descriptors were proposed to determine both the carbonyl $+\cdot \mathrm{OH}$ and gem-diol $+\cdot \mathrm{OH}$ rate constants, and the overall rate constant was calculated to be compared with the experimental data.

Due to the absence of any experimental determination of $K_{\text {hyd }}$ in the literature for organic nitrates, a specific experiment was performed to determine the hydration constant of $\alpha$-nitrooxyacetone. This was done by dissolving the compound in $\mathrm{D}_{2} \mathrm{O}$ and measuring the NMR ratios between the 
signals associated with the geminal diol configuration and the ones associated with the carbonyl form. Details on these experiments as well as the $\alpha$-nitrooxyacetone NMR spectra are presented in Sect. S3. The hydration constant for $\alpha$ nitrooxyacetone was determined to be $K_{\text {hyd }}=0.048 \pm 0.002$ at $298 \mathrm{~K}$.

\subsubsection{Database for the extended SAR}

A dataset of 24 experimental $k_{\mathrm{OH}}$ rate constants for linear ethers and 8 for cycloethers from the literature complemented by 7 organic nitrate $k_{\mathrm{OH}}$ rate constants determined in this work were used together to determine the contribution factors of each group. Table S4 compiles all compounds with the corresponding values of experimental $k_{\mathrm{OH}}$ rate constants and their associated uncertainties. The rate constants of - OH oxidation of all mentioned ethers were previously determined using competition kinetic methods. The rate constants were recalculated considering updated values for the reference compounds. For the latter, recommended values were chosen in most cases; however, when no recommendation was mentioned in the literature or when more recent studies were published, average values were calculated (Table S1). Outlier values were discarded by using Dixon's $Q$ test.

The F, G, H, and X parameters were varied simultaneously using the Microsoft ${ }^{\circledR}$ Excel $^{\circledR}$ Solver routine to solve the multivariate linear regressions in order to minimize the sum of the square difference between calculated and experimental values normalized by the experimental uncertainties (Eq. 9).

$Q=\sum_{i} \frac{\left(k_{i, \exp }-k_{i, \operatorname{sim}}\right)^{2}}{\sigma_{i}^{2}}$,

where $k_{i, \exp }$ and $k_{i, \text { sim }}$ are the experimental and simulated $k_{\mathrm{OH}}$ values, respectively, for compound $i$, and $\sigma_{i}$ is the experimental uncertainty. This target $Q$ value allowed us to give priority, in the simulations, to experimental data determined with low uncertainties, thus improving the reliability of the SAR compared to the previous developments. The experimental uncertainties were determined thoroughly for organic nitrates (Sect. 4.2) and were directly used for the SAR. For ethers, the associated experimental uncertainties were recalculated by considering not only the linear plot uncertainties but also the uncertainties associated with the values for the reference compound, using the propagation of uncertainty. For the values reported with no uncertainty, we arbitrarily assigned a $100 \%$ uncertainty to prevent an excessive contribution of unclear determinations. This was the case, for example, for all the determinations reported in the works from Anbar et al. (1966) and Eibenberger (1980).

The preexisting parameters of the SAR were not modified, and they were used as reported in Doussin and Monod (2013) and Monod and Doussin (2008). To calculate the new parameters, in a first step, a rough estimation of the ether parameters $(\mathrm{F}(-\mathrm{O}), \mathrm{G}(-\mathrm{O}-)$, and $\mathrm{X}(-\mathrm{O}-))$ was performed using our dataset by starting from different initial conditions. In a
Table 3. SAR tests on organic nitrate parameters: five case tests evaluated the nitrate group influence. Constraints imposed are the following: values fixed to 1 (i.e., no influence on the reactivity) marked by *; $\mathrm{F}\left(-\mathrm{ONO}_{2}\right)=\mathrm{G}\left(-\mathrm{ONO}_{2}\right)$ for case 3 and case 4 ; and $\mathrm{G}\left(-\mathrm{ONO}_{2}\right)=\mathrm{H}\left(-\mathrm{ONO}_{2}\right)$ for case 5 . In bold is the selected case. The slope is the correlation slope between the simulated and the experimental $k_{\mathrm{OH}}$ rate constants, and $R^{2}$ is the corresponding correlation coefficient. The $\Delta$ factor is the relative difference between the simulated and the experimental rate constant. $Q$ is the sum of the square difference between calculated and experimental values normalized by the experimental uncertainties. Efficiencies at $75 \%$ and $60 \%$ represent the percentage of organic nitrates with $|\Delta|<0.25$ and $|\Delta|<0.40$, respectively.

\begin{tabular}{lrrrrr}
\hline & Case 1 & Case 2 & Case 3 & Case 4 & Case 5 \\
\hline $\mathrm{F}\left(-\mathrm{ONO}_{2}\right)$ & 0 & 0 & $\mathbf{0 . 1 7}$ & 0.18 & 0 \\
$\mathrm{G}\left(-\mathrm{ONO}_{2}\right)$ & $1^{*}$ & 0.33 & $\mathbf{0 . 1 7}$ & 0.18 & 0.37 \\
$\mathrm{H}\left(-\mathrm{ONO}_{2}\right)$ & $1^{*}$ & $1^{*}$ & $\mathbf{1}^{*}$ & 0.92 & 0.37 \\
Slope & 1.18 & 1.18 & $\mathbf{1 . 0 1}$ & 0.98 & 0.53 \\
$R^{2}$ & 0.92 & 0.97 & $\mathbf{0 . 9 6}$ & 0.95 & 0.94 \\
$\Delta$ & -5.19 & -0.14 & $\mathbf{- 0 . 1 9}$ & 0.05 & 2.06 \\
$Q$ & 23.0 & 0.12 & $\mathbf{0 . 5 9}$ & 0.58 & 0.93 \\
Efficiency 75\% & $29 \%$ & $86 \%$ & $\mathbf{7 1 \%}$ & $57 \%$ & $14 \%$ \\
Efficiency 60\% & $43 \%$ & $100 \%$ & $\mathbf{8 6 \%}$ & $86 \%$ & $43 \%$ \\
\hline
\end{tabular}

Table 4. SAR results: new calculated neighboring effects parameters for ethers, cyclic ethers and organic nitrates (using case 3 constraints).

\begin{tabular}{lr}
\hline Parameter & Value \\
\hline $\mathrm{F}(-\mathrm{O}-)$ & 1.10 \\
$\mathrm{G}(-\mathrm{O}-)$ & 0.33 \\
$C^{\prime} 5$ (ring) & 1.43 \\
$C^{\prime}$ 6(ring) & 1.79 \\
$\mathrm{~F}\left(-\mathrm{ONO}_{2}\right)$ & 0.17 \\
$\mathrm{G}\left(-\mathrm{ONO}_{2}\right)$ & 0.17 \\
\hline
\end{tabular}

second step, a test of different constraints on organic nitrate parameters was performed using the ether parameters estimated in the first step (for isosorbide 5-mononitrate). Due to the restricted database for organic nitrates, constraints were settled on for the values of $\mathrm{F}\left(-\mathrm{ONO}_{2}\right), \mathrm{G}\left(-\mathrm{ONO}_{2}\right)$, and $\mathrm{H}(-$ $\mathrm{ONO}_{2}$ ), and five different cases were tested (Table 3 ) in order to find the best compromise between a minimum number of independent variables and a realistic parameterization of the possible long-range deactivating effects of the nitrate group. The five different cases were developed to investigate if the deactivating effect affects only the reactive sites in $\alpha$ position to the nitrate group (case 1) or reaches the reactive sites in $\beta$ position (case 2 and case 3 ) or in $\gamma$ position (case 4 and case 5). In the final step, once the optimal case was selected, all the new parameters were simultaneously adjusted using the whole dataset (Table 4). 


\subsubsection{SAR results}

The results obtained for the five cases tested are shown in Table 3. Different parameters were evaluated in order to choose the optimal case. The correlation slope between the simulated and the experimental $k_{\mathrm{OH}}$ rate constants as well as their correlation coefficient, the $Q$ values, and the relative difference between the simulated and the experimental rate constant was calculated for each organic nitrate using Eq. (10):

$\Delta=\frac{k_{\exp }-k_{\text {sim }}}{k_{\exp }}$,

where the sum of all the individual $\Delta$ factors is given in Table 3 . A value close to 0 indicates the absence of any significant bias.

In all cases, each contribution factor for organic nitrates which was varied resulted in a value lower than 1 , and the nearer to the nitrate group, the lower the value, confirming the deactivating effect of the group. Nonetheless, when cases 1,2 , and 5 were run, the calculated value for $\mathrm{F}(-$ $\mathrm{ONO}_{2}$ ) dropped to 0 , meaning a total suppression of the $\mathrm{H}$ abstraction in the $\alpha$ position, which is unlikely, thus discarding these three cases. In the two remaining cases (3 and 4), the nitrate group impacts on the reactivity up to the $\beta$ or the $\gamma$ position, respectively. Most of the evaluation parameters are very similar in both cases, but case 4 is much less constrained than case 3 , which holds only one variable (Table 3 ). Case 3 was thus selected as the optimal case. Furthermore, the value obtained for $\mathrm{H}\left(-\mathrm{ONO}_{2}\right)$ in case $4(0.92)$ is close to unity, thus showing a very slight influence of the nitrate group in the $\gamma$ position, and the difference between this value and unity potentially falls in the experimental uncertainties. The results indicate that the impact of the nitrate group on the reactivity towards $\cdot \mathrm{OH}$ radicals only affects the $\alpha$ - and the $\beta$-reactive sites. This means that the reduced reactivity (observed in Fig. 5) is caused by the electron-withdrawing effect of the nitrate group which is enhanced in the aqueous phase.

In the final step, using case 3 constraints, all the new parameters were simultaneously adjusted using the whole dataset, and the results are listed in Table 4. The resulting neighboring factors for organic nitrates are $\mathrm{F}\left(-\mathrm{ONO}_{2}\right)=\mathrm{G}(-$ $\left.\mathrm{ONO}_{2}\right)=0.17$. For ethers, the results show that $\mathrm{F}(-\mathrm{O}-$ )$=1.10$, which is a value higher than unity, and $\mathrm{G}(-\mathrm{O}-$ )$=0.33$, which is lower than 1 . This reveals an influence similar to the $-\mathrm{OH}$ group, for which $\mathrm{F}(-\mathrm{OH})=2.10$ and $\mathrm{G}(-$ $\mathrm{OH})=0.44$. For these groups, the $\alpha$ position is activating due to a positive mesomeric effect, whereas the $\beta$ position is deactivating due to the oxygen electron-withdrawing effect. Furthermore, the resulting value for $\mathrm{X}(-\mathrm{O}-)=1.79$ reflects that the presence of oxygen atoms in a ring increases the reactivity of the molecule.

Figure 6 shows the correlation between the calculated versus the experimental $k_{\mathrm{OH}}$ values, and it is compared to the $1: 1$ regression line. It shows good linearity covering a wide

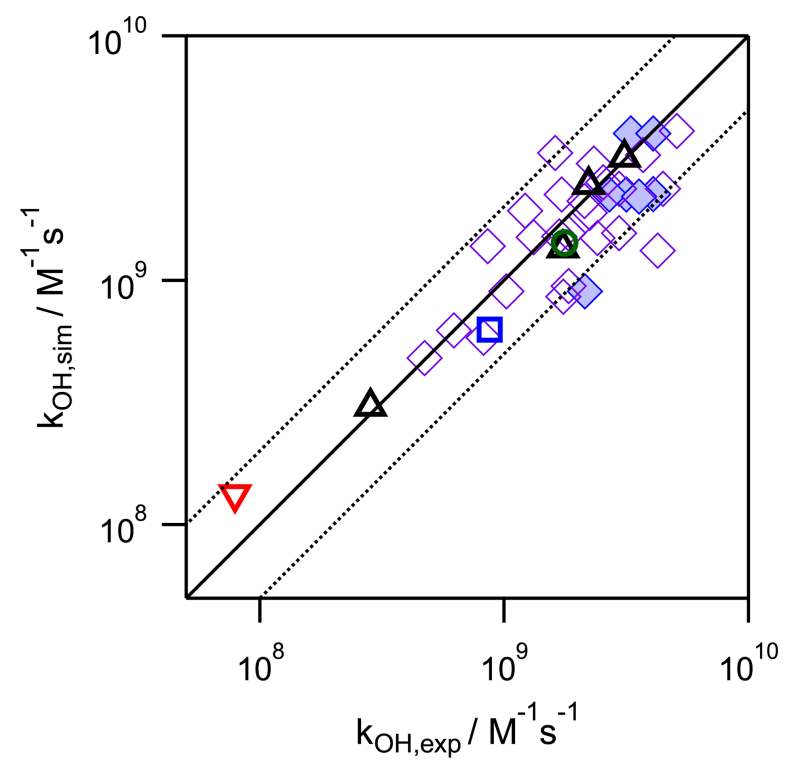

\begin{tabular}{|llll|}
\hline $\boldsymbol{\Delta}$ & Alkyl Nitrates & $\mathbf{D}$ & 1-Nitrooxy-2-propanol \\
$\boldsymbol{\nabla}$ & $\alpha$-Nitrooxyacetone & $\circ$ & Isosorbide 5-mononitrate \\
$\diamond$ & Ethers & $\diamond$ & Cycloethers \\
\hline
\end{tabular}

Figure 6. Correlation plot between the experimental and the simulated aqueous-phase $\cdot \mathrm{OH}$-oxidation rate constants for organic nitrates and ethers. The solid line corresponds to the $1: 1$ regression, and the dotted lines represent the limits where the simulated rate constants deviate from the experimental ones by a factor of 2 .

range of reactivities (over 2 orders of magnitude). The efficiency of the proposed extended SAR for organic nitrates, ethers, and cycloethers was studied by calculating the relative difference between the simulated and the experimental rate constants ( $\Delta$ factor, see Eq. 10). Overall, for $51 \%$ of the experimental values, the efficiency was better than $75 \%$ $(|\Delta|<0.25)$ and better than $60 \%(|\Delta|<0.4)$ for $69 \%$ of experimental values. For organic nitrates, six out of the seven studied molecules presented an efficiency better than $60 \%$. Compared to the previous versions of the SAR tested for other functional groups (Doussin and Monod, 2013; Monod and Doussin, 2008), the efficiencies were slightly lower. This may be due to the way the SAR parameters were calculated in this work. While the previous SAR aimed at minimizing $\Delta$ for a maximum number of values, in this work, a good efficiency was prioritized for the experimental values with low uncertainties using Eq. (9). Several arguments provide some evidence on the reliability of the application of the SAR to other compounds: (i) there are only a few discrepancies (deviations by a factor of 2) between the experimental and simulated values, even for low-weighted experimental values; (ii) the resolved parameters were chemically coherent; (iii) a wide range of reactivities were covered ( 2 orders of magnitude); and (iv) the good agreement between the simulated and the experimental $k_{\mathrm{OH}}$ values (within uncertainties) for 
isosorbide 5-mononitrate (Table 2). Being a highly complex polyfunctional compound (bearing two ring, two ether, one alcohol, and one nitrate groups), its good result gives some validation of the extended SAR application to polyfunctional compounds.

Due to the restricted database used here to build the extended SAR, the $-\mathrm{ONO}_{2}$ contribution factors could not elucidate the differences between the $\mathrm{F}\left(-\mathrm{ONO}_{2}\right)$ and $\mathrm{G}\left(-\mathrm{ONO}_{2}\right)$ contribution factors. We acknowledge that the differences between the two factors may be significant as it happens for the gas-phase reactions (Jenkin et al., 2018). In order to better assess the detailed influence of the nitrate group to each carbon, more experimental determinations of the kinetic rate constants should be done for the reactivity of these compounds in the aqueous phase. However, as we have found a good agreement between the simulated values and the experimental ones, the present SAR is useful to estimate the importance of aqueous-phase $\cdot \mathrm{OH}$ oxidation for organic nitrates in the atmosphere.

The extended SAR was used to calculate the $\cdot \mathrm{OH}-$ oxidation rate constants of several atmospherically relevant compounds, such as hydroxy nitrates, isoprene nitrates, and terpene nitrates. The atmospheric fate of these molecules is discussed in the next section.

\section{Atmospheric implications}

In light of these results on the aqueous-phase $\cdot \mathrm{OH}$ oxidation of organic nitrates, we estimated the importance of these processes in the atmosphere. We used the developed SAR to predict the $k_{\mathrm{OH}}$ rate constants of other atmospherically relevant organic nitrates to evaluate if the aqueous-phase $\cdot \mathrm{OH}$ oxidation has a significant role in their atmospheric lifetimes. Some of the evaluated organic nitrates have been detected in field campaigns (Beaver et al., 2012; Li et al., 2018); they are expected products from isoprene or monoterpenes photooxidation (Lee et al., 2014), or they are small polyfunctional nitrates that may be formed by the fragmentation of terpene nitrates or by the oxidation of alkyl nitrates (PicquetVarrault et al., 2020; Treves and Rudich, 2003). By selecting organic nitrates potentially relevant to atmospheric chemistry, as well as those mentioned in the literature, we listed 49 compounds that were divided into seven categories depending on their functionalization and chemical structure: 6 alkyl nitrates, 7 hydroxy nitrates, 7 ketonitrates, 5 aldehyde nitrates, 5 nitrooxy carboxylic acids, 7 other polyfunctional nitrates containing more than one oxygenated group, and 12 terpene nitrates corresponding to highly oxidized organic nitrates formed by the oxidation of terpenes, such as $\alpha$ - and $\beta$-pinene, limonene, and myrcene. Table S5 appends all the studied molecules and their chemical structures and properties under the scenarios studied below.

Inspired by the work of Epstein and Nizkorodov (2012), considering various aqueous-phase scenarios from cloud/fog conditions to wet aerosols, we evaluated the atmospheric phase partition of these 49 relevant organic nitrates, and we estimated the importance of the $\cdot \mathrm{OH}$-oxidation reaction in the aqueous phase. Finally, the atmospheric multiphase $\cdot \mathrm{OH}-$ oxidation lifetimes of these compounds under cloud/fog conditions were calculated and compared to their gas-phase lifetimes.

\subsection{Aqueous- and aerosol-phase partition of organic nitrates}

The partition of atmospherically relevant organic nitrates between the aqueous, gas, and aerosol phases was evaluated. The partition between the gas and aqueous phases was calculated using Eq. (11):

$K_{\mathrm{gas} / \mathrm{aq}}=\frac{n_{\mathrm{X}, \mathrm{gas}}}{n_{\mathrm{X}, \mathrm{aq}}}=\frac{\rho_{\mathrm{W}}}{L_{\mathrm{WC}} K_{\mathrm{H}} R T}$,

where $n_{\mathrm{X}, \text { gas }}$ and $n_{\mathrm{X} \text {, aq }}$ are the number of moles of compound $\mathrm{X}$ that are present in the gas and aqueous phases, respectively; $\rho_{\mathrm{W}}$ is the density of water (in $\mathrm{g} \mathrm{m}^{-3}$ ); $L_{\mathrm{WC}}$ is the liquid water content ( $\mathrm{LWC}$ in $\mathrm{g} \mathrm{m}^{-3}$ ); $K_{\mathrm{H}}$ is the effective Henry's law constant (in mol L-1 $\mathrm{atm}^{-1}$ ); $R$ is the ideal gas constant equal to $0.082 \mathrm{~atm} \mathrm{~L} \mathrm{~mol}^{-1} \mathrm{~K}^{-1}$; and $T$ is the temperature in kelvin.

The partition between the gas and the aerosol phases was calculated using Eq. (12):

$K_{\mathrm{gas} / \mathrm{aer}}=\frac{n_{\mathrm{X}, \mathrm{gas}}}{n_{\mathrm{X}, \mathrm{aer}}}=\frac{\overline{M_{\mathrm{aer}}} \gamma_{\mathrm{X}} P_{\mathrm{X}}^{\mathrm{vap}}}{C_{\mathrm{aer}} R T}$,

where $n_{\mathrm{X} \text {,aer }}$ is the number of moles of compound $\mathrm{X}$ that are present in the aerosol phase, $\overline{M_{\text {aer }}}$ is the mean organic molar mass in the aerosol phase (in $\mathrm{g} \mathrm{mol}^{-1}$ ), $\gamma_{\mathrm{X}}$ is the activity coefficient of compound $\mathrm{X}, P_{\mathrm{X}}^{\mathrm{vap}}$ is its saturation vapor pressure (in atm), and $C_{\text {aer }}$ is the total organic aerosol mass concentration (in $\mathrm{g} \mathrm{m}^{-3}$ ). Combining Eqs. (11) and (12), one obtains the fraction of any compound in each phase. The concentration of a compound in each phase depends on the values of $K_{\mathrm{H}}$ and $P_{\mathrm{X}}^{\mathrm{vap}}$.

The partition was studied for two representative atmospheric conditions: (i) under typical cloud/fog conditions with a $L W C=0.35 \mathrm{~g} \mathrm{~m}^{-3}$ (Fig. 7a) and (ii) under wet aerosol conditions with a lower LWC $=3 \times 10^{-5} \mathrm{~g} \mathrm{~m}^{-3}$ (Fig. 7b) (Herrmann et al., 2015). The aerosol mass concentration was set to $C_{\text {aer }}=1 \times 10^{-5} \mathrm{~g} \mathrm{~m}^{-3}$ with a $\overline{M_{\text {aer }}}=200 \mathrm{~g} \mathrm{~mol}^{-1}$ and $T=298 \mathrm{~K}$. The values of $K_{\mathrm{H}}$ were calculated using the SAR developed by Raventos-Duran et al. (2010), and the values of $P_{\mathrm{X}}^{\text {vap }}$ were calculated with the group contribution method by Nannoolal et al. (2004, 2008). Both values were taken from the GECKO-A website (http://geckoa.lisa.u-pec. fr/generateur_form.php, last access: 16 May 2020). The activity coefficient was assumed to be 1 due to the lack of experimental or simulated data, while, in a real organic aerosol, $\gamma_{\mathrm{X}}$ can range from 0.8 to 10 (Wania et al., 2014). It is worth 
(a)

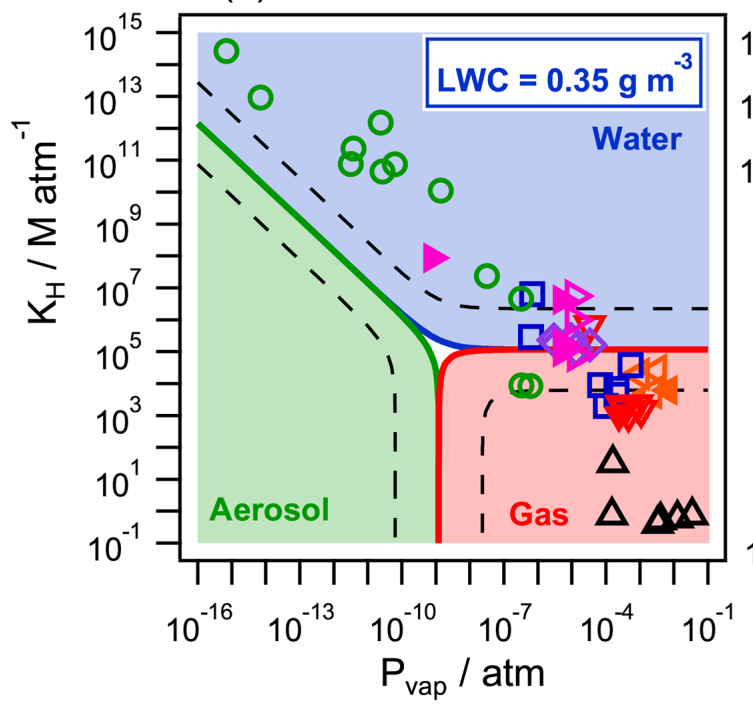

(b)

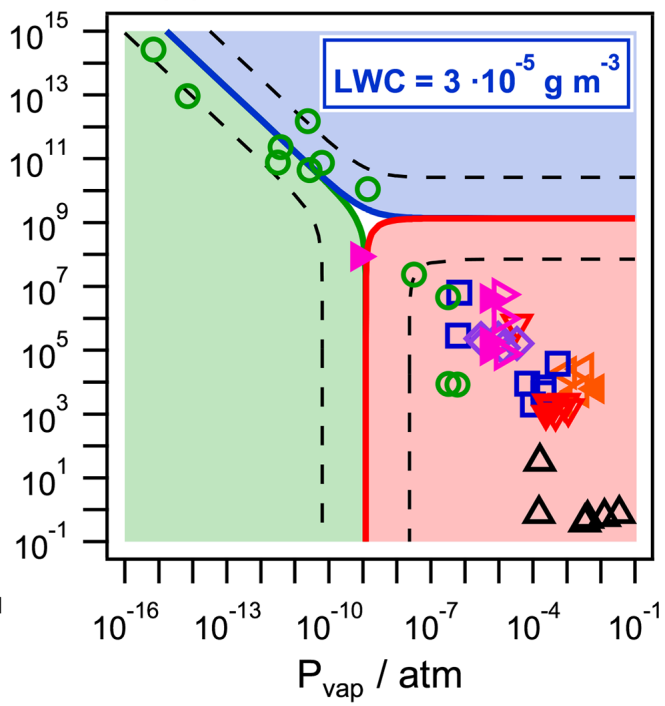

\begin{tabular}{|llll|}
\hline$\Delta$ & Alkyl Nitrates & $\Delta$ & Aldehyde Nitrates \\
$\boldsymbol{\square}$ & Hydroxy Nitrate & $\boldsymbol{\nabla}$ & Ketonitrates \\
$\diamond$ & Nitrooxy carboxylic acids & 0 & Terpene Nitrates \\
$\nabla$ & More Polyfunctionalized Nitrates
\end{tabular}

Figure 7. Partition of atmospherically relevant organic nitrates in the aqueous phase (blue), the gas phase (red), and the aerosol phase (green)

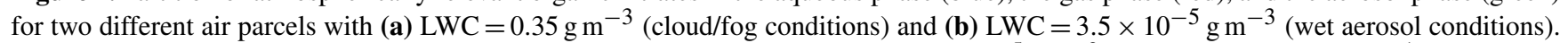

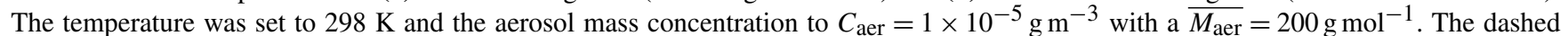
lines represent the limits where the concentration of one compound exceeds $95 \%$ in each phase. Filled markers represent organic nitrates derived from isoprene.

noting that, in the atmosphere, the equilibrium may not be instantaneous. In their kinetic flux model, Shiraiwa and Seinfeld (2012) demonstrate that equilibrium is achieved on the order of seconds or minutes for the phase partitioning of relatively high volatility organic compounds into liquid particles, while the equilibration timescale ranges from hours to days for semisolid viscous particles, low volatility species, or large particle sizes and thus can be subject to equilibrium shifts by faster chemical reactions in each phase. However, these considerations are beyond the scope of the study, as the goal was to determine how aqueous-phase chemistry can affect the fate of organic nitrates even at very low LWC. Thus, Eq. (12) was used to understand if the partition into the aerosol phase is important compared to the aqueous phase and the gas phase, under the two investigated conditions.

Figure 7 shows the partition of the selected 49 relevant organic nitrates in the three phases. Under cloud/fog conditions ( $\mathrm{LWC}=0.35 \mathrm{~g} \mathrm{~m}^{-3}$, Fig. 7a), all compounds partition between the aqueous phase (blue) and the gas phase (red). The presence of terpene nitrates in the aqueous phase is highly significant: 10 out of the 12 studied molecules are present in the aqueous phase in proportions higher than $95 \%$. Under the same conditions, small functionalized nitrates (with five carbons or less) partition in both phases depending on their functionalization. No significant partition to the aerosol phase is observed under these conditions. Under wet aerosol conditions ( $\mathrm{LWC}=3 \times 10^{-5} \mathrm{~g} \mathrm{~m}^{-3}$, Fig. 7b), small organic nitrates are only present in the gas phase (red). High-molecular-mass compounds such as terpene nitrates equally partition between the aqueous (blue) and the aerosol phases (green).

These results show that, depending on their reactivity, the compounds which mainly partition into the aqueous phase may show a different atmospheric lifetime compared to the one assessed if only the gas-phase reactions are considered.

\section{2 $\cdot$ OH-oxidation multiphase lifetimes of organic nitrates}

The atmospheric reactivity of each of the 49 organic nitrates with $\cdot \mathrm{OH}$ radicals in the gas phase was compared to the aqueous-phase one using the $W$ value defined in Eq. (13):

$W=\frac{\frac{\mathrm{d} n_{\mathrm{X}, \mathrm{gas}}}{\mathrm{d} t}}{\frac{\mathrm{d} n_{\mathrm{X}, \mathrm{aq}}}{\mathrm{d} t}}=\frac{\rho_{W}}{L_{\mathrm{WC}} K_{\mathrm{H}} R T} \frac{k_{\mathrm{OH}, \mathrm{gas}}[\mathrm{OH}]_{\mathrm{gas}}}{k_{\mathrm{OH}, \mathrm{aq}}[\mathrm{OH}]_{\mathrm{aq}}}$,

where $k_{\mathrm{OH} \text {,gas }}$ and $k_{\mathrm{OH} \text {,aq }}$ are the gas-phase and aqueousphase $\cdot$ OH-oxidation rate constants, respectively (in $\mathrm{mol} \mathrm{L}^{-1} \mathrm{~s}^{-1}$, with $\mathrm{L}$ being the volume unit of air and atmospheric water for $k_{\mathrm{OH} \text {,gas }}$ and $k_{\mathrm{OH} \text {,aq }}$, respectively). $[\mathrm{OH}]_{\text {gas }}$ and $[\mathrm{OH}]_{\mathrm{aq}}$ (in $\mathrm{mol} \mathrm{L}^{-1}$ of air and $\mathrm{mol} \mathrm{L}^{-1}$ of 
atmospheric water, respectively) are the concentrations of hydroxyl radicals in the gas and the aqueous phases.

Figure 8 compares the $\cdot \mathrm{OH}$ reactivity of organic nitrates in the aqueous and the gas phases for cloud/fog conditions (Fig. 8a) and for wet aerosol conditions (Fig. 8b) described in the previous section. The $\cdot \mathrm{OH}$ radical concentrations were set to $1.4 \times 10^{6}$ molecules $\mathrm{cm}^{-3}\left(2.32 \times 10^{-15} \mathrm{~mol} \mathrm{~L}^{-1}\right)$ in the gas phase and $10^{-14} \mathrm{~mol} \mathrm{~L}^{-1}$ in the aqueous phase (Tilgner et al., 2013). The $k_{\mathrm{OH} \text {,aq }}$ rate constants were calculated using the extended SAR developed in this work (Eq. 6). Neighboring factors for nitrate and ether groups were those calculated in this work (Table 4), while all other parameters were taken from Doussin and Monod (2013) and Monod and Doussin (2008). Equation (8) was employed for compounds containing carbonyl groups. For organic nitrates containing a carboxylic acid functional group, the contributions of both the protonated molecule and its conjugated base were considered. For these compounds, the $\mathrm{pH}$ was set to 5 and 3 for cloud/fog conditions and for wet aerosol conditions, respectively. The experimental $k_{\mathrm{OH} \text {,gas }}$ values were used when available (references in Fig. 5). They were complemented, when necessary, using the gas-phase SAR developed by Jenkin et al. (2018). The GROHME method was used to obtain the $K_{\text {hyd }}$ for compounds containing a carbonyl group (Raventos-Duran et al., 2010). Both the simulated $k_{\mathrm{OH} \text {,gas }}$ and $K_{\text {hyd }}$ were taken from the GECKO-A website (http://geckoa.lisa.u-pec.fr/generateur_form.php, last access: 16 May 2020).

The $y$ axis of Fig. 8 represents the effective Henry's law constant for each molecule. The ratio of gas- to aqueousphase $\cdot \mathrm{OH}$-oxidation rate constant (in liters of air per liter of atmospheric water) is shown in the $x$ axis. Isopleths show the $W$ values. A $W$ value lower than 1 (blue background) implies that more than $50 \%$ of the target compound is consumed in the aqueous phase. The two dashed isopleths above and below the $W=1$ isopleth represent the limits for aqueous- and gas-phase processing exceeding $95 \%$, respectively.

Under cloud/fog conditions (Fig. 8a), most of the studied compounds present important aqueous-phase processing. Most of the terpene nitrates are highly functionalized and have a high molecular weight; they are almost absent in the gas phase, and their $\cdot \mathrm{OH}$ oxidation is solely governed by their aqueous-phase kinetics. Only two terpene nitrates, which are first-generation reaction products of $\alpha$ - and $\beta$-pinene $\mathrm{NO}_{3} \cdot$ oxidation ( $\mathrm{Li}$ et al., 2018), have a sufficiently low $K_{\mathrm{H}}$ for their $\cdot \mathrm{OH}$ removal to take place mostly in the gas phase $(\approx 93 \%)$ due to their low functionalization.

For smaller functionalized organic nitrates, the gas-phase - $\mathrm{OH}$-oxidation reaction is important. However, one can see that an important fraction of the compounds is located between the dashed isopleths, meaning that both the gas- and the aqueous-phase processing are relevant in their atmospheric loss towards $\cdot \mathrm{OH}$ radicals. This behavior is highly related to the functionalization of the organic nitrate. For small ketonitrates and aldehyde nitrates, their loss is mainly taking place in the gas phase. With the increase of polarity, such as for hydroxy nitrates, and even more substantially for nitrooxy carboxylic acids, the aqueous-phase $\cdot \mathrm{OH}$ oxidation becomes more important. For organic nitrates with more than one oxidized group, their processing in the aqueous phase becomes the major loss process. This observation could be relevant for atmospheric chemistry since some products of isoprene photooxidation are highly functionalized organic nitrates (Fisher et al., 2016).

Figure $8 \mathrm{~b}$ shows the relative importance of aqueousphase $\cdot \mathrm{OH}$ oxidation under wet aerosol conditions (LWC $=$ $3 \times 10^{-5} \mathrm{~g} \mathrm{~m}^{-3}$ ). Under these conditions, the aqueous-phase - $\mathrm{OH}$ oxidation is relevant for most of the terpene nitrates. However, under these conditions, these compounds should also partition to the aerosol phase (Fig. 7b). In this phase, not only the $\cdot \mathrm{OH}$-oxidation kinetic rate constants may differ from the gas- and the aqueous-phase ones but also other oxidants, such as singlet oxygen or the triplet excited state of dissolved organic matter, can play a crucial role in the atmospheric loss of these compounds (Kaur and Anastasio, 2018; Manfrin et al., 2019). Therefore, this chemistry should be included to precisely evaluate the atmospheric loss of terpene nitrates at these conditions. For small organic nitrates, the gas-phase $\cdot \mathrm{OH}$-oxidation reaction remains their major loss pathway. Figure 8 shows that for most of the compounds for which the aqueous phase is the major loss process, the ratio $k_{\mathrm{OH}, \mathrm{gas}} / k_{\mathrm{OH} \text {,aq }}$ is higher than 1 , thus inducing a slower consumption in the aqueous phase. This point is specifically investigated in Fig. 9 and Table S5.

Multiphase $\cdot \mathrm{OH}$-oxidation lifetimes $\left(\tau_{\mathrm{OH} \text {,multiphase }}\right)$ were calculated for each organic nitrate by considering the $\cdot \mathrm{OH}$ reactivity both in the atmospheric aqueous phase and gas phase using Eq. (14):

$$
\begin{aligned}
& \tau_{\mathrm{OH}, \text { multiphase }} \\
& =\frac{1}{\Phi_{\mathrm{aq}} k_{\mathrm{OH}, \mathrm{aq}}[\mathrm{OH}]_{\mathrm{aq}}+\Phi_{\mathrm{gas}} k_{\mathrm{OH}, \text { gas }}[\mathrm{OH}]_{\mathrm{gas}}},
\end{aligned}
$$

where $\Phi_{\text {aq }}$ and $\Phi_{\text {gas }}$ are the fractions of each compound present in the aqueous and gas phases, respectively.

Under cloud/fog conditions, the multiphase $\cdot \mathrm{OH}-$ oxidation lifetimes range from hours to several days, and they are compiled in Table S5. Their $\tau_{\mathrm{OH}}$,multiphase is dependent on the chemical structure of the molecules. Large molecules, such as terpene nitrates, or compounds with reactive groups such as aldehyde nitrates show low -OH-oxidation lifetimes (from 6 to $27 \mathrm{~h}$ ). For most of the other organic nitrates, their lifetimes range from $1 \mathrm{~d}$ to 1 week, such as primary alkyl nitrates, hydroxy nitrates, ketonitrates with more than three carbon atoms, or organic nitrates containing more than one different functional group. The last category contains four important isoprene-derived nitrates for which multiphase $\cdot \mathrm{OH}$-oxidation lifetimes are $1 \mathrm{~d}$ for $\mathrm{C}_{5}$ dihydroxy dinitrate, $1 \mathrm{~d}$ for methacrolein nitrate, and 2 and $4 \mathrm{~d}$ for the two isomeric forms of methylvinyl 
(a)

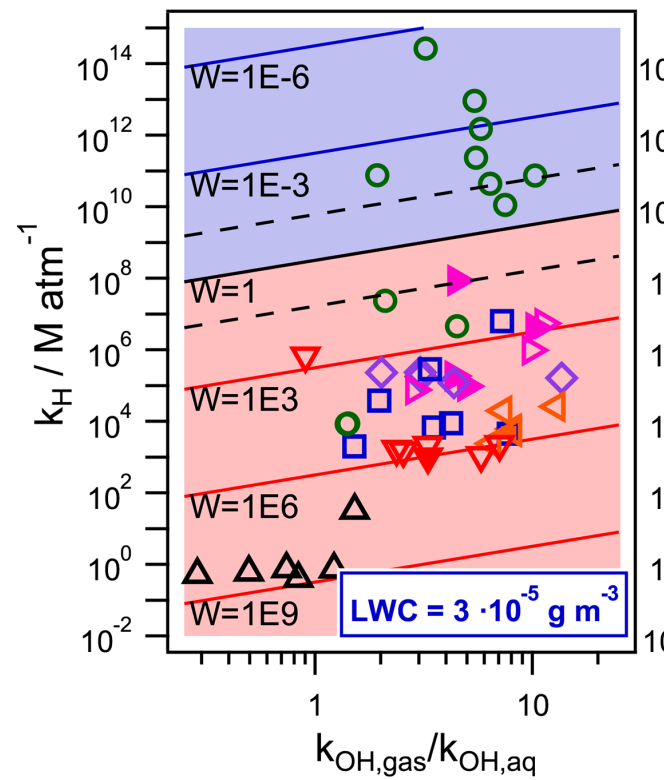

$\Delta$ Alkyl Nitrates

口 Hydroxy Nitrates

- Nitrooxy carboxylic acids

$\checkmark$ More Polyfunctionalized Nitrates (b)

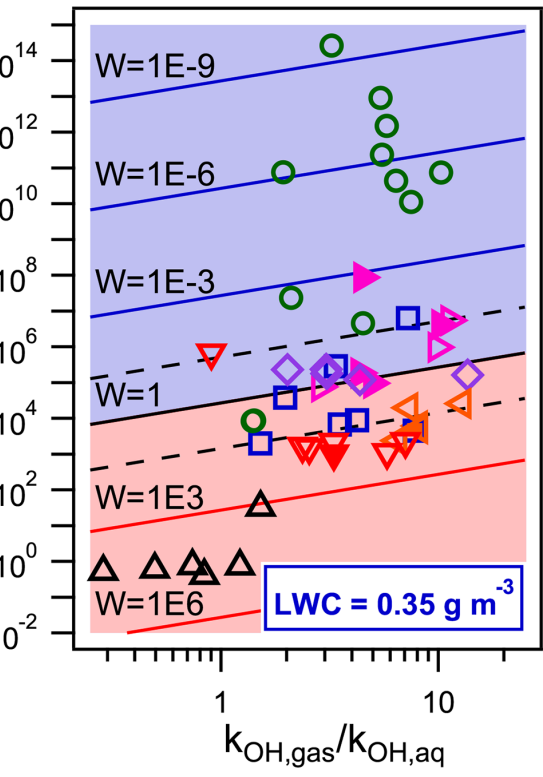

$\triangleleft$ Aldehyde Nitrates

$\nabla$ Ketonitrates

- Terpene Nitrates

Figure 8. Gas-aqueous partition and reactivity (towards $\cdot \mathrm{OH}$-oxidation) of 49 organic nitrates for two different air parcels with (a) $\mathrm{LWC}=0.35 \mathrm{~g} \mathrm{~m}^{-3}$ (cloud/fog conditions) and (b) $\mathrm{LWC}=3.5 \times 10^{-5} \mathrm{~g} \mathrm{~m}^{-3}$ (wet aerosol conditions) at $298 \mathrm{~K}$. The $\cdot \mathrm{OH}$ radical concentrations were set to $2.32 \times 10^{-15} \mathrm{~mol} \mathrm{~L}^{-1}\left(1.4 \times 10^{6}\right.$ molecules $\left.\mathrm{cm}^{-3}\right)$ in the gas phase and to $10^{-14} \mathrm{~mol} \mathrm{~L}^{-1}$ in the aqueous phase. Filled markers represent organic nitrates derived from isoprene.

nitrate. The most persistent molecules towards $\cdot \mathrm{OH}$ that are present are small ( $\leq 3$ carbon atoms), they bear reactivityinhibiting functional groups such as carboxylic groups, or they combine more than one nitrate group. The multiphase -OH-oxidation lifetimes for these molecules can reach $28 \mathrm{~d}$. Isopropyl nitrate and $\alpha$-nitrooxyacetone, compounds which have been widely detected in the atmosphere, present very low atmospheric reactivity towards $\cdot \mathrm{OH}$ radicals $(24$ and 19 d, respectively).

Among the selected organic nitrates, some compounds bear their nitrate group on a tertiary carbon; these species may undergo very fast hydrolysis (Darer et al., 2011; Jacobs et al., 2014). Their lifetimes with respect to hydrolysis range from 1 min to $8.8 \mathrm{~h}$ (Takeuchi and $\mathrm{Ng}, 2019$ ). Therefore, for most of these compounds, their hydrolysis is likely the main loss reaction in the atmosphere. Nevertheless, as mentioned in Sect. 1, the non-hydrolyzable fraction of organic nitrates ranges from $68 \%$ to $91 \%$ for $\alpha$-pinene- and $\beta$-pinene-derived organic nitrates; thus, for most of these organic nitrates this reaction does not occur.

Photolysis is also a likely sink for organic nitrates, mostly for carbonyl nitrates. Gas-phase photolysis lifetimes have been experimentally determined or simulated for 11 of these compounds, and they range from 0.5 to $15 \mathrm{~h}$ (Barnes et al., 1993; Müller et al., 2014; Picquet-Varrault et al., 2020;
Suarez-Bertoa et al., 2012). At these rates, gas-phase photolysis is expected to be the main chemical loss process for lowmolecular-weight carbonyl nitrates. On the other hand, to our knowledge, no aqueous-phase photolysis lifetimes have been experimentally determined for carbonyl nitrates. Meanwhile, Romonosky et al. (2015) investigated molar absorptivity of a series of $\beta$-hydroxynitrates in the aqueous phase, and, assuming similar quantum yields as in the gas phase, they calculated the photolysis rate constant ratios between the gas and aqueous phases. Using their approach, aqueous-phase photolysis is likely a major sink for water-soluble carbonyl nitrates as it likely occurs for most isoprene-derived nitrates. However, their results show that $\cdot \mathrm{OH}$ oxidation in the aqueous phase or the gas phase is a more significant loss process than photolysis for $\beta$-hydroxynitrates. This could be the case for atmospherically relevant species such as $\mathrm{C}_{5}$ dihydroxy dinitrate or for terpene nitrates. For the latter, their $\cdot \mathrm{OH}-$ oxidation lifetimes fall in the same range as the photolysis lifetimes reported for carbonyl nitrates in the gas phase; thus, both processes may be relevant for terpene nitrates including those containing carbonyl groups, but further experimental studies would deserve attention to confirm this.

To assess the impact that aqueous-phase $\cdot \mathrm{OH}$ oxidation has on organic nitrate lifetimes, the $\cdot \mathrm{OH}$-oxidation lifetime relative difference was calculated $\left(\tau_{\mathrm{OH}, \mathrm{dif}}\right)$ for each com- 
(a)

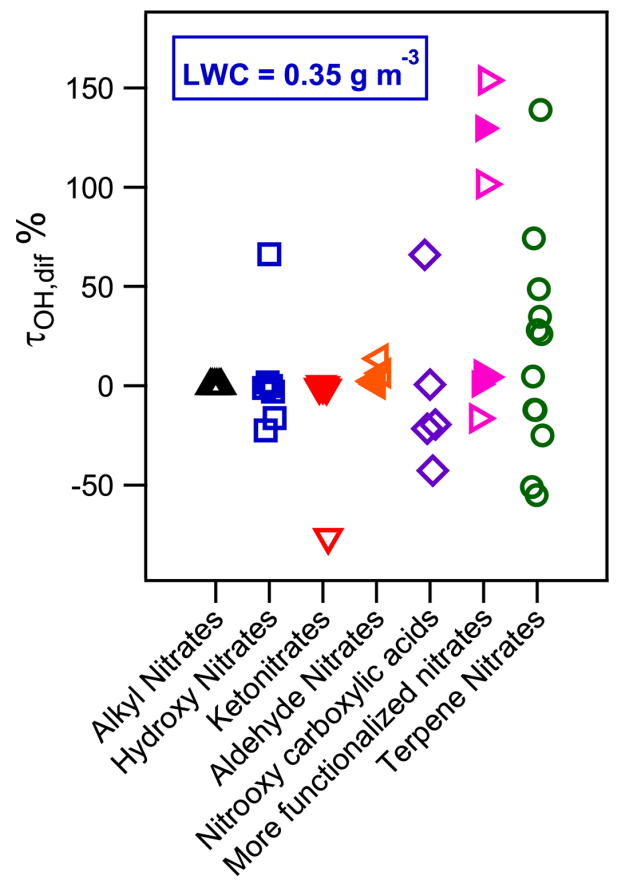

(b)

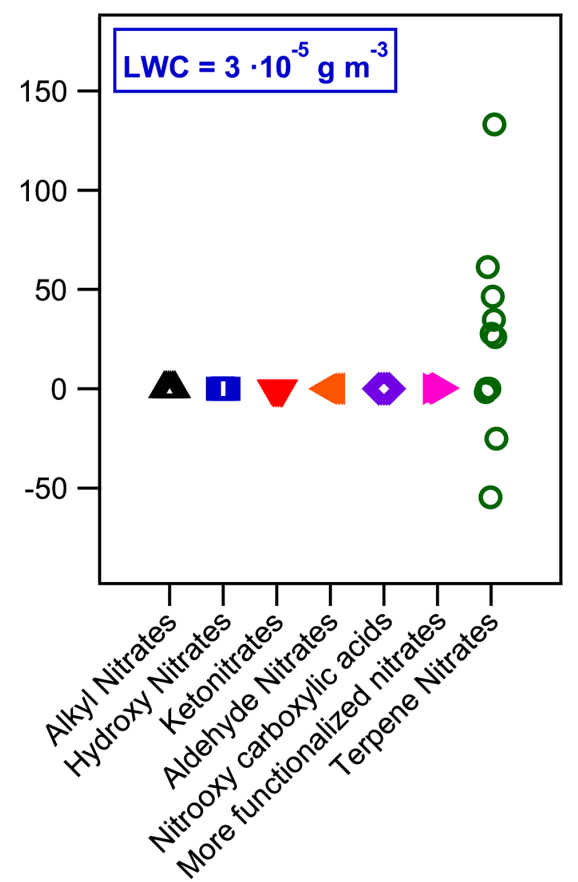

Figure 9. Relative difference of $\cdot \mathrm{OH}$-oxidation lifetimes between an air parcel with and without liquid water at $(\mathbf{a}) \mathrm{LWC}=0.35 \mathrm{~g} \mathrm{~m}^{-3}$ and (b) $\mathrm{LWC}=3 \times 10^{-5} \mathrm{~g} \mathrm{~m}^{-3}$ for atmospherically relevant organic nitrates. Filled markers represent organic nitrates derived from isoprene.

pound using Eq. (15):

$\tau_{\mathrm{OH}, \mathrm{dif}} \%=\frac{\tau_{\mathrm{OH}, \text { multiphase }}-\tau_{\mathrm{OH}, \text { gas phase }}}{\tau_{\mathrm{OH}, \text { gas phase }}} \cdot 100$,

where $\tau_{\mathrm{OH}}$, multiphase derives from Eq. (14), and $\tau_{\mathrm{OH} \text {,gas phase }}$ is the $\cdot \mathrm{OH}$-oxidation lifetime of a compound considering only the gas phase. For molecules barely partitioning into the aqueous phase, the $\tau_{\mathrm{OH} \text {,dif }}$ value is close to zero. For molecules partitioning into the aqueous phase, a positive value of $\tau_{\mathrm{OH} \text {,dif }}$ indicates that the aqueous-phase reactivity increases the atmospheric lifetime of the molecule, while a negative value implies a faster atmospheric removal via aqueous-phase reactivity.

Figure $9 \mathrm{a}$ shows $\tau_{\mathrm{OH} \text {,dif }}$ for the studied organic nitrates. For the families of compounds such as alkyl nitrates, most of the ketonitrates and aldehyde nitrates, which barely partition into the aqueous phase, show that their lifetimes remain unchanged compared to the gas-phase reactivity. Substantial atmospheric loss is expected for hydroxy nitrates, nitrooxy carboxylic acids, and organic nitrates with more than one oxidized group as in the case of some isoprene and terpene nitrates. Their $\tau_{\mathrm{OH} \text {,dif }}$ ranges from $-75 \%$ to $+155 \%$, implying that their global $\cdot \mathrm{OH}$-oxidation lifetimes may be either shortened or lengthened when the aqueous phase is considered, depending on the chemical structure of the molecule. Figure 9 shows that for most of these compounds, especially many terpene nitrates and some polyfunctionalized isoprene nitrates, their atmospheric lifetimes significantly increase (by a factor that can exceed $140 \%$ ), thus showing that their atmospheric lifetimes should be even longer than what is predicted from gas-phase reactions. This effect might be enhanced considering that aqueous $\cdot \mathrm{OH}$ concentrations might be lower than the one used in Eq. (14), i.e., $1 \times 10^{-14} \mathrm{M}$. This value corresponds to aqueous concentrations of $\cdot \mathrm{OH}$ in polluted/urban cloud droplets (Tilgner et al., 2013). Nevertheless, for remote cloud droplets or wet aerosols, the aqueous - $\mathrm{OH}$ concentration might be 2 to 10 times lower (Arakaki et al., 2013). These lower concentrations would induce an increase in the $\cdot \mathrm{OH}$-oxidation lifetimes of molecules partitioning into the aqueous phase.

Figure $9 \mathrm{~b}$ shows that under wet aerosol conditions, only terpene nitrate $\cdot \mathrm{OH}$-oxidation lifetimes are affected when considering the aqueous phase. Under this LWC condition, the proposed terpene nitrates partition both in the aqueous phase and the aerosol phase (Fig. 7b). In the aerosol phase, not only the $\cdot \mathrm{OH}$-oxidation kinetic rate constants may differ from the gas- and the aqueous-phase ones but also other oxidants can play a crucial role in the atmospheric loss of these compounds (Kaur and Anastasio, 2018; Manfrin et al., 2019). Further studies comprising this reactivity are thus needed to better understand the fate of organic nitrates in all atmospheric phases. 


\section{Conclusions}

A new competition kinetic method was developed to accurately determine the aqueous-phase $\cdot \mathrm{OH}$-oxidation rate constants of species with low reactivity such as organic nitrates, using a robust reference compound such as methanol. The method was applied to determine new $\cdot \mathrm{OH}$-oxidation kinetics of seven organic nitrates (isopropyl nitrate, isobutyl nitrate, 1-pentyl nitrate, isopentyl nitrate, $\alpha$-nitrooxyacetone, 1-nitrooxy-2-propanol, isosorbide 5-mononitrate), which are compounds for which the aqueous-phase $\cdot \mathrm{OH}$-oxidation reaction was investigated for the first time. It was found that the nitrate group provokes an important deactivation of the -OH attack, similar to the corresponding gas-phase reactions but enhanced by solvent kinetic effects. A previously developed SAR method was extended to include the nitrate group, allowing the prediction of aqueous-phase kinetics for these atmospherically relevant compounds. The resulting SAR parameters for the nitrate group confirmed the extreme deactivating effect of the nitrate group, up to two adjacent carbon atoms. The achieved SAR was then used to evaluate the multiphase fate of 49 organic nitrates of atmospheric relevance, including hydroxy nitrates, ketonitrates, aldehyde nitrates, nitrooxy carboxylic acids, and more functionalized organic nitrates. Among these compounds, polyfunctional organic nitrates were found to be extremely impacted by the aqueous-phase $\cdot \mathrm{OH}$ oxidation not only due to their very high water solubility but also due to their reduced reactivity in this solvent. For $50 \%$ of the proposed organic nitrates for which the $\cdot \mathrm{OH}$ reaction occurs mainly in the aqueous phase (more than $50 \%$ of the overall removal), their $\cdot \mathrm{OH}$-oxidation lifetimes increased by $20 \%$ to $155 \%$ under cloud/fog conditions. This was even more pronounced for terpene nitrates: for $83 \%$ of them, the reactivity towards $\cdot \mathrm{OH}$ occurred mostly $(>98 \%)$ in the aqueous phase under fog/cloud conditions, while for $60 \%$ of these terpene nitrates their lifetimes increased by $25 \%$ to $140 \%$ compared to their gas-phase reactivity. We demonstrate that these effects are of importance under cloud/fog conditions but also under wet aerosol conditions, especially for the terpene nitrates. These results suggest that considering aqueous-phase $\cdot \mathrm{OH}$-oxidation reactivity of biogenic organic nitrates is necessary to improve the predictions of their atmospheric fates and transport, and they should result in a better assessment of the distribution of air pollution, $\mathrm{SOA}$ formation, and $\mathrm{NO}_{x}$ chemistry. 
Appendix A: Determining aqueous-phase $k_{\mathrm{OH}}$ by monitoring the headspace with the PTR-MS

Since the organic compounds were diluted in the aqueous phase, headspace analyses were based on the direct proportionality between water and gas-phase concentrations of the analytes (Karl et al., 2003). Furthermore, the influence of the gas-phase $\cdot \mathrm{OH}$ oxidation was negligible in our system. Equation (1) can be written as

$\ln \frac{[\mathrm{X}]_{0(\mathrm{~g})}}{[\mathrm{X}]_{t(\mathrm{~g})}}=\frac{k_{\mathrm{OH}, \mathrm{X}}}{k_{\mathrm{OH}, \mathrm{M}}} \cdot \ln \frac{[\mathrm{M}]_{0(\mathrm{~g})}}{[\mathrm{M}]_{t(\mathrm{~g})}}$,

where $\ln \left([\mathrm{X}]_{0(\mathrm{~g})} /[\mathrm{X}]_{t(\mathrm{~g})}\right)$ and $\ln \left([\mathrm{M}]_{0(\mathrm{~g})} /[\mathrm{M}]_{t(\mathrm{~g})}\right)$ represent the gas-phase concentration relative decay of the target compound and methanol, respectively. The gas-phase relative decays of both methanol and (in some cases) the target compound were monitored by the PTR-MS instrument. The PTRMS measured quantities in counts per second (cps), which can be related to absolute headspace concentrations using Eq. (A2),

$[\mathrm{X}]_{\mathrm{g}}=\frac{1}{k_{R_{\text {rate }} t_{R_{\text {time }}}}} \cdot \frac{\sum \operatorname{cps}\left(\mathrm{X}^{+}\right)}{\operatorname{cps}\left(\mathrm{H}_{3} \mathrm{O}^{+}\right)}$,

where $\sum \operatorname{cps}\left(\mathrm{X}^{+}\right)$is the sum of the counts per second of all the fragments which correspond to compound $\mathrm{X}$; the cps $\left(\mathrm{H}_{3} \mathrm{O}^{+}\right)$values are the counts per second of the hydronium ions that protonate the molecule; $k_{R_{\text {rate }}}$ is the protonation rate constant for compound $\mathrm{X}$ in the PTR-MS drift tube; and $t_{R_{\text {time }}}$ is the time spent by the molecule in the drift tube. Combining Eqs. (A1) and (A2), one obtains Eq. (2). 
Code availability. The detailed molecule calculations are available upon request.

Data availability. PTR-MS and UHPLC-UV raw data from the experimental method are available at https://doi.org/10.7910/DVN/LDS7B3 (González-Sánchez, 2021). Data related to the extended SAR or the "Atmospheric implications" section can be requested from Juan Miguel GonzálezSánchez (juanmiguelgs93@gmail.com) or from Anne Monod (anne-monod@univ-amu.fr).

Supplement. The supplement related to this article is available online at: https://doi.org/10.5194/acp-21-4915-2021-supplement.

Author contributions. JMGS developed the experimental kinetic method. NB provided the UV-Vis data for organic nitrates. JMGS and SR developed the UHPLC-UV method for organic nitrates. JM and BTR developed the PTR-MS method for organic nitrates. JLC performed the organic nitrates synthesis and the NMR experiments to obtain the $\alpha$-nitrooxyacetone $K_{\text {hyd }}$. JMGS and AM built the SAR extension to include nitrate and ether contribution factors. NB and JW significantly contributed to the SAR construction. CMV wrote an ad hoc helper code to apply the SAR to the more complex molecules. AM and JLC lead the project. JMGS and AM wrote the article with inputs from all coauthors.

Competing interests. The authors declare that they have no conflict of interest.

Acknowledgements. The authors thank Richard Valorso for his help using the GECKO-A modeling tool and Benjamin Chazeau for his help and insightful discussions.

Financial support. This project has received funding from the European Union's Horizon 2020 research and innovation programme under the Marie Skłodowska-Curie (grant no. 713750). It has been carried out with the financial support of the Regional Council of Provence-Alpes-Côte d'Azur and with the financial support of the A*MIDEX (grant no. ANR- 11-IDEX-000102), funded by the Investissements d'Avenir project funded by the French Government, managed by the French National Research Agency (ANR). This study also received funding from the French CNRS-LEFE-CHAT (Programme National-Les Enveloppes Fluides et l'Environnement-Chimie Atmosphérique - Project "MULTINITRATES") and from the program ANR-PRCI (ANR-18-CE920038-02) - Project "PARAMOUNT".

Review statement. This paper was edited by James Roberts and reviewed by two anonymous referees.

\section{References}

Adams, G. E., Boag, J. W., and Michael, B. D.: Reactions of the hydroxyl radical: Part 2. - Determination of absolute rate constants, Trans. Faraday Soc., 61, 1417-1424, https://doi.org/10.1039/TF9656101417, 1965.

Alam, M. S., Rao, B. S. M., and Janata, E.: •OH reactions with aliphatic alcohols: Evaluation of kinetics by direct optical absorption measurement. A pulse radiolysis study, Radiat. Phys. Chem., 67, 723-728, https://doi.org/10.1016/S0969806X(03)00310-4, 2003.

Anbar, M., Meyerstein, D., and Neta, P.: Reactivity of aliphatic compounds towards hydroxyl radicals, J. Chem. Soc. B Phys. Org., 17, 742-747, https://doi.org/10.1039/J29660000742, 1966.

Aoki, N., Inomata, S., and Tanimoto, H.: Detection of C1C5 alkyl nitrates by proton transfer reaction time-of-flight mass spectrometry, Int. J. Mass Spectrom., 263, 12-21, https://doi.org/10.1016/j.ijms.2006.11.018, 2007.

Arakaki, T., Anastasio, C., Kuroki, Y., Nakajima, H., Okada, K., Kotani, Y., Handa, D., Azechi, S., Kimura, T., Tsuhako, A., and Miyagi, Y.: A General Scavenging Rate Constant for Reaction of Hydroxyl Radical with Organic Carbon in Atmospheric Waters, Environ. Sci. Technol., 47, 8196-8203, https://doi.org/10.1021/es401927b, 2013.

Atkinson, R.: Kinetics of the gas-phase reactions of $\mathrm{OH}$ radicals with alkanes and cycloalkanes, Atmos. Chem. Phys., 3, 22332307, https://doi.org/10.5194/acp-3-2233-2003, 2003.

Atkinson, R. and Aschmann, S. M.: Rate constants for the reactions of the $\mathrm{OH}$ radical with the propyl and butyl nitrates and 1-nitrobutane at $298 \pm 2$ k, Int. J. Chem. Kinet., 21, 1123-1129, https://doi.org/10.1002/kin.550211205, 1989.

Atkinson, R., Aschmann, S. M., Carter, W. P. L., Winer, A. M., and Pitts, J. N.: Alkyl Nitrate Formation from the NOx-Air Photooxidations of C2-C8 n-Alkanes, J. Phys. Chem., 86, 4563-4569, https://doi.org/10.1021/j100220a022, 1982.

Atkinson, R., Baulch, D. L., Cox, R. A., Hampson, R. F., Kerr, J. A., and Troe, J.: Evaluated Kinetic and Photochemical Data for Atmospheric Chemistry: Supplement IV. IUPAC Subcommittee on Gas Kinetic Data Evaluation for Atmospheric Chemistry, J. Phys. Chem. Ref. Data, 21, 1125-1568, https://doi.org/10.1063/1.555918, 1992.

Atkinson, R., Baulch, D. L., Cox, R. A., Hampson, R. F., Kerr, J. A., Rossi, M. J., and Troe, J.: Evaluated Kinetic, Photochemical and Heterogeneous Data for Atmospheric Chemistry: Supplement V. IUPAC Subcommittee on Gas Kinetic Data Evaluation for Atmospheric Chemistry, J. Phys. Chem. Ref. Data, 26, 521-1011, https://doi.org/10.1063/1.556011, 1997.

Barnes, I., Becker, K. H., and Zhu, T.: Near UV absorption spectra and photolysis products of difunctional organic nitrates: Possible importance as $\mathrm{NO}_{x}$ reservoirs, J. Atmos. Chem., 17, 353-373, https://doi.org/10.1007/BF00696854, 1993.

Beaver, M. R., Clair, J. M. St., Paulot, F., Spencer, K. M., Crounse, J. D., LaFranchi, B. W., Min, K. E., Pusede, S. E., Wooldridge, P. J., Schade, G. W., Park, C., Cohen, R. C., and Wennberg, P. O.: Importance of biogenic precursors to the budget of organic nitrates: observations of multifunctional organic nitrates by CIMS and TD-LIF during BEARPEX 2009, Atmos. Chem. Phys., 12, 5773-5785, https://doi.org/10.5194/acp-12-5773-2012, 2012.

Becker, K. H. and Wirtz, K.: Gas phase reactions of alkyl nitrates with hydroxyl radicals under tropospheric conditions in 
comparison with photolysis, J. Atmos. Chem., 9, 419-433, https://doi.org/10.1007/BF00114754, 1989.

Bedjanian, Y., Morin, J., and Romanias, M. N.: Kinetics of the reactions of $\mathrm{OH}$ radicals with n-butyl, isobutyl, n-pentyl and 3-methyl-1-butyl nitrates, Atmos. Environ., 155, 29-34, https://doi.org/10.1016/j.atmosenv.2017.02.014, 2017.

Bedjanian, Y., Morin, J., and Romanias, M. N.: Reactions of $\mathrm{OH}$ radicals with 2-methyl-1-butyl, neopentyl and 1-hexyl nitrates. Structure-activity relationship for gas-phase reactions of $\mathrm{OH}$ with alkyl nitrates: An update, Atmos. Environ., 180, 167-172, https://doi.org/10.1016/j.atmosenv.2018.03.002, 2018.

Clemitshaw, K. C., Williams, J., Rattigan, O. V., Shallcross, D. E., Law, K. S., and Anthony Cox, R.: Gas-phase ultraviolet absorption cross-sections and atmospheric lifetimes of several C2C5 alkyl nitrates, J. Photochem. Photobiol. A, 102, 117-126, https://doi.org/10.1016/S1010-6030(96)04458-9, 1997.

Darer, A. I., Cole-Filipiak, N. C., Connor, A. E. O., and Elrod, M. J.: Formation and Stability of Atmospherically Relevant IsopreneDerived Organosulfates and Organonitrates, Environ. Sci. Technol., 45, 1895-1902, 2011.

Doussin, J.-F. and Monod, A.: Structure-activity relationship for the estimation of $\mathrm{OH}$-oxidation rate constants of carbonyl compounds in the aqueous phase, Atmos. Chem. Phys., 13, 1162511641, https://doi.org/10.5194/acp-13-11625-2013, 2013.

Duncianu, M., David, M., Kartigueyane, S., Cirtog, M., Doussin, J.-F., and Picquet-Varrault, B.: Measurement of alkyl and multifunctional organic nitrates by proton-transfer-reaction mass spectrometry, Atmos. Meas. Tech., 10, 1445-1463, https://doi.org/10.5194/amt-10-1445-2017, 2017.

Eibenberger, J.: Pulse Radiolysis Investigations Concerning the Formation and Oxidation of Organic Radicals in Aqueous Solutions, University of Vienna, Vienna, 1980.

Elliot, A. J. and Simsons, A. S.: Rate constants for reactions of hydroxyl radicals as a function of temperature, Radiat. Phys. Chem., 24, 229-231, https://doi.org/10.1016/01465724(84)90056-6, 1984.

Epstein, S. A. and Nizkorodov, S. A.: A comparison of the chemical sinks of atmospheric organics in the gas and aqueous phase, Atmos. Chem. Phys., 12, 8205-8222, https://doi.org/10.5194/acp12-8205-2012, 2012.

Fisher, J. A., Jacob, D. J., Travis, K. R., Kim, P. S., Marais, E. A., Chan Miller, C., Yu, K., Zhu, L., Yantosca, R. M., Sulprizio, M. P., Mao, J., Wennberg, P. O., Crounse, J. D., Teng, A. P., Nguyen, T. B., St. Clair, J. M., Cohen, R. C., Romer, P., Nault, B. A., Wooldridge, P. J., Jimenez, J. L., CampuzanoJost, P., Day, D. A., Hu, W., Shepson, P. B., Xiong, F., Blake, D. R., Goldstein, A. H., Misztal, P. K., Hanisco, T. F., Wolfe, G. M., Ryerson, T. B., Wisthaler, A., and Mikoviny, T.: Organic nitrate chemistry and its implications for nitrogen budgets in an isoprene- and monoterpene-rich atmosphere: constraints from aircraft (SEAC4RS) and ground-based (SOAS) observations in the Southeast US, Atmos. Chem. Phys., 16, 5969-5991, https://doi.org/10.5194/acp-16-5969-2016, 2016.

Getoff, N.: Radiation- and photoinduced degradation of pollutants in water. A comparative study, Int. J. Radiat. Appl. Instrumentation. Part, 37, 673-680, https://doi.org/10.1016/13590197(91)90166-Y, 1991.

Gligorovski, S., Rousse, D., George, C. H., and Herrmann, H.: Rate constants for the $\mathrm{OH}$ reactions with oxygenated organic com- pounds in aqueous solution, Int. J. Chem. Kinet., 41, 309-326, https://doi.org/10.1002/kin.20405, 2009.

González-Sánchez, J. M.: Replication Data for the application of the competition kinetic method in: On the importance of atmospheric loss of organic nitrates by aqueous-phase .OH oxidation, Harvard Dataverse, V1, https://doi.org/10.7910/DVN/LDS7B3, 2021.

Greenstock, C. L., Ng, M., and Hunt, J. W.: Pulse Radiolysis Studies of Reactions of Primary Species in Water with Nucleic Acid Derivatives, in: Radiation Chemistry, pp. 397-417, American Chemical Society, Washington, D.C., 1968.

Herrmann, H.: Kinetics of Aqueous Phase Reactions Relevant for Atmospheric Chemistry, Chem. Rev., 103, 4691-4716, https://doi.org/10.1021/cr020658q, 2003.

Herrmann, H., Schaefer, T., Tilgner, A., Styler, S. A., Weller, C., Teich, M., and Otto, T.: Tropospheric Aqueous-Phase Chemistry: Kinetics, Mechanisms, and Its Coupling to a Changing Gas Phase, Chem. Rev., 115, 4259-4334, https://doi.org/10.1021/cr500447k, 2015.

Hu, K. S., Darer, A. I., and Elrod, M. J.: Thermodynamics and kinetics of the hydrolysis of atmospherically relevant organonitrates and organosulfates, Atmos. Chem. Phys., 11, 8307-8320, https://doi.org/10.5194/acp-11-8307-2011, 2011.

Jacobs, M. I., Burke, W. J., and Elrod, M. J.: Kinetics of the reactions of isoprene-derived hydroxynitrates: gas phase epoxide formation and solution phase hydrolysis, Atmos. Chem. Phys., 14 8933-8946, https://doi.org/10.5194/acp-14-8933-2014, 2014.

Jenkin, M. E., Valorso, R., Aumont, B., Rickard, A. R., and Wallington, T. J.: Estimation of rate coefficients and branching ratios for gas-phase reactions of $\mathrm{OH}$ with aliphatic organic compounds for use in automated mechanism construction, Atmos. Chem. Phys., 18, 9297-9328, https://doi.org/10.5194/acp18-9297-2018, 2018.

Karl, T., Yeretzian, C., Jordan, A. and Lindinger, W.: Dynamic measurements of partition coefficients using proton-transfer-reaction mass spectrometry (PTR-MS), Int. J. Mass Spectrom., 223224, 383-395, https://doi.org/10.1016/S1387-3806(02)00927-2, 2003.

Kaur, R. and Anastasio, C.: First Measurements of Organic Triplet Excited States in Atmospheric Waters, Environ. Sci. Technol. 52, 5218-5226, https://doi.org/10.1021/acs.est.7b06699, 2018.

Kiendler-Scharr, A., Mensah, A. A., Friese, E., Topping, D., Nemitz, E., Prevot, A. S. H., Äijälä, M., Allan, J., Canonaco, F., Canagaratna, M., Carbone, S., Crippa, M., Dall Osto, M., Day, D. A., De Carlo, P., Di Marco, C. F., Elbern, H., Eriksson, A., Freney, E., Hao, L., Herrmann, H., Hildebrandt, L., Hillamo, R., Jimenez, J. L., Laaksonen, A., McFiggans, G., Mohr, C., O’Dowd, C., Otjes, R., Ovadnevaite, J., Pandis, S. N., Poulain, L., Schlag, P., Sellegri, K., Swietlicki, E., Tiitta, P., Vermeulen, A., Wahner, A., Worsnop, D., and Wu, H. C.: Ubiquity of organic nitrates from nighttime chemistry in the European submicron aerosol, Geophys. Res. Lett., 43, 7735-7744, https://doi.org/10.1002/2016GL069239, 2016.

Koner, A. L., Pischel, U., and Nau, W. M.: Kinetic solvent effects on hydrogen abstraction reactions, Org. Lett., 9, 2899-2902, https://doi.org/10.1021/o1071165g, 2007.

Lee, A. K. Y., Adam, M. G., Liggio, J., Li, S.-M., Li, K., Willis, M. D., Abbatt, J. P. D., Tokarek, T. W., Odame-Ankrah, C. A., Osthoff, H. D., Strawbridge, K., and Brook, J. R.: A large contribution of anthropogenic organo-nitrates to secondary organic 
aerosol in the Alberta oil sands, Atmos. Chem. Phys., 19, 1220912219, https://doi.org/10.5194/acp-19-12209-2019, 2019.

Lee, L., Teng, A. P., Wennberg, P. O., Crounse, J. D., and Cohen, R. C.: On rates and mechanisms of $\mathrm{OH}$ and $\mathrm{O}_{3}$ reactions with isoprene-derived hydroxy nitrates, J. Phys. Chem. A, 118, 16221637, https://doi.org/10.1021/jp4107603, 2014.

Li, R., Wang, X., Gu, R., Lu, C., Zhu, F., Xue, L., Xie, H., Du, L., Chen, J., and Wang, W.: Identification and semiquantification of biogenic organic nitrates in ambient particulate matters by UHPLC/ESI-MS, Atmos. Environ., 176, 140-147, https://doi.org/10.1016/j.atmosenv.2017.12.038, 2018.

Lindinger, W., Hansel, A., and Jordan, A.: Proton-transfer-reaction mass spectrometry (PTR-MS): On-line monitoring of volatile organic compounds at pptv levels, Chem. Soc. Rev., 27, 347-354, https://doi.org/10.1039/a827347z, 1998.

Liu, S., Shilling, J. E., Song, C., Hiranuma, N., Zaveri, R. A., and Russell, L. M.: Hydrolysis of organonitrate functional groups in aerosol particles, Aerosol Sci. Technol., 46, 1359-1369, https://doi.org/10.1080/02786826.2012.716175, 2012.

Manfrin, A., Nizkorodov, S. A., Malecha, K. T., Getzinger, G. J., McNeill, K., and Borduas-Dedekind, N.: Reactive Oxygen Species Production from Secondary Organic Aerosols: The Importance of Singlet Oxygen, Environ. Sci. Technol., 53, 85538562, https://doi.org/10.1021/acs.est.9b01609, 2019.

Monod, A. and Doussin, J. F.: Structure-activity relationship for the estimation of $\mathrm{OH}$-oxidation rate constants of aliphatic organic compounds in the aqueous phase: alkanes, alcohols, organic acids and bases, Atmos. Environ., 42, 7611-7622, https://doi.org/10.1016/j.atmosenv.2008.06.005, 2008.

Monod, A., Poulain, L., Grubert, S., Voisin, D., and Wortham, H.: Kinetics of $\mathrm{OH}$-initiated oxidation of oxygenated organic compounds in the aqueous phase: New rate constants, structure-activity relationships and atmospheric implications, Atmos. Environ., 39, 7667-7688, https://doi.org/10.1016/j.atmosenv.2005.03.019, 2005.

Motohashi, N. and Saito, Y.: Competitive Measurement of Rate Constants for Hydroxyl Radical Reactions Using Radiolytic Hydroxylation of Benzoate, Chem. Pharm. Bull., 41, 1842-1845, https://doi.org/10.1248/cpb.41.1842, 1993.

Müller, J.-F., Peeters, J., and Stavrakou, T.: Fast photolysis of carbonyl nitrates from isoprene, Atmos. Chem. Phys., 14, 24972508, https://doi.org/10.5194/acp-14-2497-2014, 2014

Nannoolal, Y., Rarey, J., Ramjugernath, D., and Cordes, W.: Estimation of pure component properties: Part 1. Estimation of the normal boiling point of non-electrolyte organic compounds via group contributions and group interactions, Fluid Phase Equilib., 226, 45-63, https://doi.org/10.1016/j.fluid.2004.09.001, 2004.

Nannoolal, Y., Rarey, J., and Ramjugernath, D.: Estimation of pure component properties part 3. Estimation of the vapor pressure of non-electrolyte organic compounds via group contribution and group interactions, Fluid Phase Equilib., 269, 117-133, https://doi.org/10.1016/j.fluid.2008.04.020, 2008.

Neyens, E. and Baeyens, J.: A review of classic Fenton's peroxidation as an advanced oxidation technique, J. Hazard. Mater., 98, 33-50, https://doi.org/10.1016/S0304-3894(02)00282-0, 2003.

Picquet-Varrault, B., Suarez-Bertoa, R., Duncianu, M., Cazaunau, M., Pangui, E., David, M., and Doussin, J.-F.: Photolysis and oxidation by $\mathrm{OH}$ radicals of two carbonyl nitrates: 4-nitrooxy-2- butanone and 5-nitrooxy-2-pentanone, Atmos. Chem. Phys., 20, 487-498, https://doi.org/10.5194/acp-20-487-2020, 2020.

Raventos-Duran, T., Camredon, M., Valorso, R., Mouchel-Vallon, C., and Aumont, B.: Structure-activity relationships to estimate the effective Henry's law constants of organics of atmospheric interest, Atmos. Chem. Phys., 10, 7643-7654, https://doi.org/10.5194/acp-10-7643-2010, 2010.

Reuvers, A. P., Greenstock, C. L., Borsa, J., and Chapman, J. D.: Studies on the mechanism of chemical radioprotection by dimethyl sulphoxide, Int. J. Radiat. Biol., 24, 533-536, https://doi.org/10.1080/09553007314551431, 1973.

Romer Present, P. S., Zare, A., and Cohen, R. C.: The changing role of organic nitrates in the removal and transport of $\mathrm{NO}_{x}$, Atmos. Chem. Phys., 20, 267-279, https://doi.org/10.5194/acp-20-2672020, 2020.

Romonosky, D. E., Nguyen, L. Q., Shemesh, D., Nguyen, T. B., Epstein, S. A., Martin, D. B. C., Vanderwal, C. D., Gerber, R. B., and Nizkorodov, S. A.: Absorption spectra and aqueous photochemistry of $\beta$-hydroxyalkyl nitrates of atmospheric interest, Mol. Phys., 113, 2179-2190, https://doi.org/10.1080/00268976.2015.1017020, 2015.

Rudakov, E. S., Volkova, L. K., and Tret'yakov, V. P.: Low selectivity of reactions of $\mathrm{OH}$-radicals with alkanes in aqueous solution, React. Kinet. Catal. Lett., 16, 33-337, 1981.

Sander, R.: Compilation of Henry's law constants (version 4.0) for water as solvent, Atmos. Chem. Phys., 15, 4399-4981, https://doi.org/10.5194/acp-15-4399-2015, 2015.

Schaefer, T., Schindelka, J., Hoffmann, D., and Herrmann, H.: Laboratory kinetic and mechanistic studies on the $\mathrm{OH}$-initiated oxidation of acetone in aqueous solution, J. Phys. Chem. A, 116, 6317-6326, https://doi.org/10.1021/jp2120753, 2012.

Shiraiwa, M. and Seinfeld, J. H.: Equilibration timescale of atmospheric secondary organic aerosol partitioning, Geophys. Res. Lett., 39, L24801, https://doi.org/10.1029/2012GL054008, 2012.

Suarez-Bertoa, R., Picquet-Varrault, B., Tamas, W., Pangui, E., and Doussin, J. F.: Atmospheric fate of a series of carbonyl nitrates: Photolysis frequencies and $\mathrm{OH}$-oxidation rate constants, Environ. Sci. Technol., 46, 12502-12509, https://doi.org/10.1021/es302613x, 2012.

Takeuchi, M. and Ng, N. L.: Chemical composition and hydrolysis of organic nitrate aerosol formed from hydroxyl and nitrate radical oxidation of $\alpha$-pinene and $\beta$-pinene, Atmos. Chem. Phys., 19, 12749-12766, https://doi.org/10.5194/acp-19-127492019, 2019.

Talukdar, R. K., Burkholder, J. B., Hunter, M., Gilles, M. K., Roberts, J. M., and Ravishankara, A. R.: Atmospheric fate of several alkyl nitrates: Part 2. UV absorption cross-sections and photodissociation quantum yields, J. Chem. Soc. - Faraday Trans., 93, 2797-2805, https://doi.org/10.1039/a701781b, 1997.

Thomas, J. K.: Rates of reaction of the hydroxyl radical, Trans. Faraday Soc., 61, 702-707, https://doi.org/10.1039/tf9656100702, 1965.

Tilgner, A., Bräuer, P., Wolke, R., and Herrmann, H.: Modelling multiphase chemistry in deliquescent aerosols and clouds using CAPRAM3.0i, J. Atmos. Chem., 70, 221-256, https://doi.org/10.1007/s10874-013-9267-4, 2013.

Treves, K. and Rudich, Y.: The atmospheric fate of C3-C6 hydroxyalkyl nitrates, J. Phys. Chem. A, 107, 7809-7817, https://doi.org/10.1021/jp035064l, 2003. 
Wängberg, I., Barnes, I., and Becker, K. H.: Atmospheric chemistry of bifunctional cycloalkyl nitrates, Chem. Phys. Lett., 261, 138144, https://doi.org/10.1016/0009-2614(96)00857-3, 1996.

Wania, F., Lei, Y. D., Wang, C., Abbatt, J. P. D., and Goss, K.U.: Novel methods for predicting gas-particle partitioning during the formation of secondary organic aerosol, Atmos. Chem. Phys., 14, 13189-13204, https://doi.org/10.5194/acp-14-131892014, 2014.

Williams, J. A., Cooper, W. J., Mezyk, S. P., and Bartels, D. M.: Absolute rate constants for the reaction of the hydrated electron, hydroxyl radical and hydrogen atom with chloroacetones in water, Radiat. Phys. Chem., 65, 327-334, https://doi.org/10.1016/S0969-806X(02)00351-1, 2002.
Willson, R. L., Greenstock, C. L., Adams, G. E., Wageman, R., and Dorfman, L. M.: The standardization of hydroxyl radical rate data from radiation chemistry, Int. J. Radiat. Phys. Chem., 3, 211-220, https://doi.org/10.1016/0020-7055(71)90023-4, 1971.

Wolfenden, B. S. and Willson, R. L.: Radical-cations as reference chromogens in kinetic studies of one-electron transfer reactions: Pulse radiolysis studies of 2,2' -azinobis-(3- ethylbenzthiazoline6-sulphonate), J. Chem. Soc. Perkin Trans., 2, 805-812, https://doi.org/10.1039/p29820000805, 1982.

Zhu, T., Barnes, I., and Becker, K. H.: Relative-rate study of the gas-phase reaction of hydroxy radicals with difunctional organic nitrates at $298 \mathrm{~K}$ and atmospheric pressure, J. Atmos. Chem., 13, 301-311, https://doi.org/10.1007/BF00058137, 1991. 